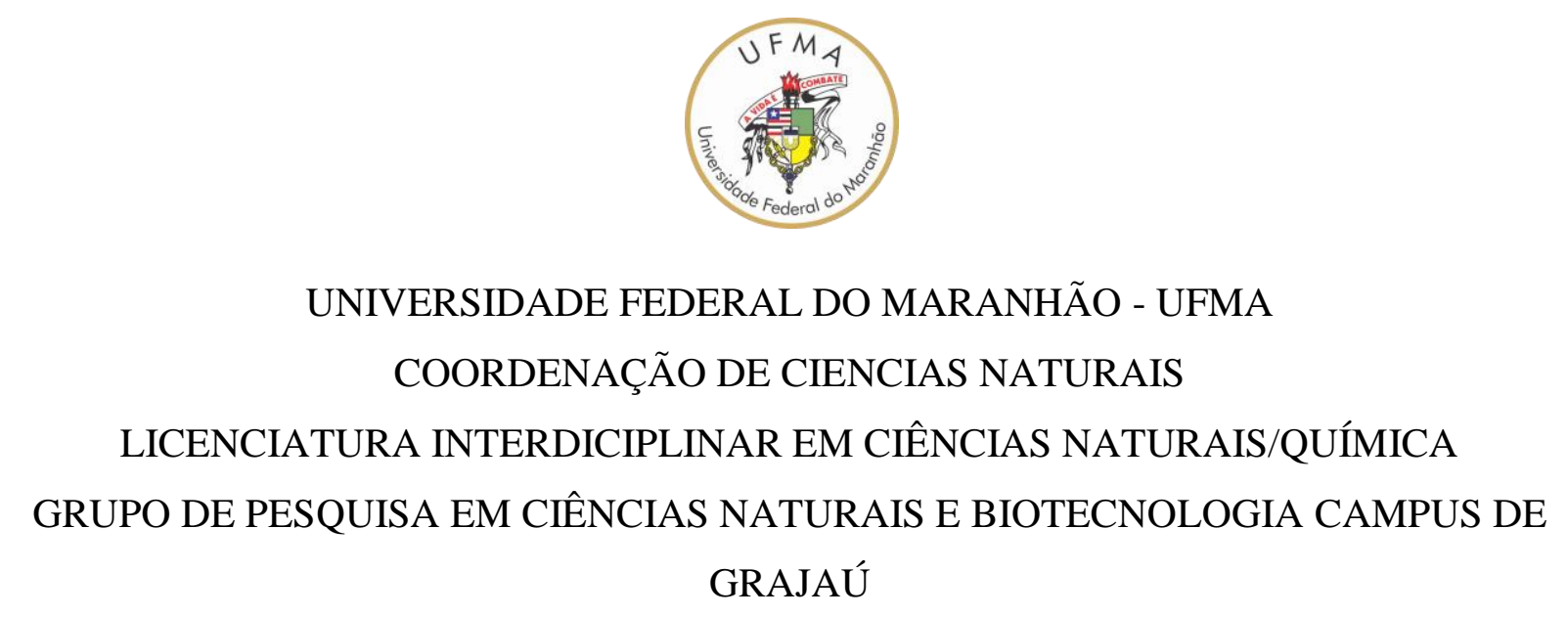

JOABE LIMA ARAÚJO

DOCKING MOLECULAR E AVALIAÇÃO DA ATIVIDADE ANTILEISHMANIA IN VITRO DE UM COMPLEXO METÁLICO DE RUTÊNIO COM EPIISOPILOTURINA E ÓXIDO NÍTRICO 
JOABE LIMA ARAÚJO

DOCKING MOLECULAR E AVALIAÇÃO DA ATIVIDADE ANTILEISHMANIA IN VITRO DE UM COMPLEXO METÁLICO DE RUTÊNIO COM EPIISOPILOTURINA E ÓXIDO NÍTRICO

Trabalho de Conclusão de Curso apresentado à coordenação do Curso de Licenciatura Plena em Ciências Naturais/Química como requisito para Conclusão do Curso.

Orientador: Prof. Dr. Jefferson Almeida Rocha 
Ficha gerada por meio do SIGAA/Biblioteca com dados fornecidos pelo(a) autor(a). Núcleo Integrado de Bibliotecas/UFMA

Araújo, Joabe Lima.

DOCKING MOLECULAR E AVALIAÇĀO DA ATIVIDADE

ANTILEISHMANIA IN VITRO DE UM COMPLEXO METÁLICO DE RUTÊNIO

COM EPIISOPILOTURINA E ÓXIDO NÍTRICO / Joabe Lima Araújo.

- 2019 .

$46 \mathrm{f}$.

Orientador(a): Jefferson Almeida Rocha.

Curso de Ciências Naturais - Quimica, Universidade

Federal do Maranhão, Grajaú, 2019.

1. Docking molecular. 2. Doenças negligenciadas. 3 .

Leishmania major. I. Rocha, Jefferson Almeida. II.

Título. 


\section{DOCKING MOLECULAR E AVALIAÇÃO DA ATIVIDADE ANTILEISHMANIA IN VITRO DE UM COMPLEXO METÁLICO DE RUTÊNIO COM EPIISOPILOTURINA E ÓXIDO NÍTRICO}

Trabalho de Conclusão de Curso apresentado à coordenação do Curso de Licenciatura Plena em Ciências Naturais/Química como requisito para Conclusão do Curso.

\section{BANCA AVALIADORA}

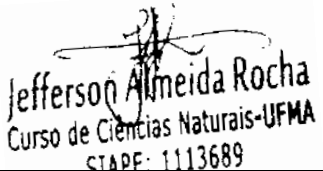

\section{Professor Jefferson Almeida Rocha (Orientador)}

Doutor em Biotecnologia pela Rede Nordeste de Biotecnologja - RENORBIO

\section{Professora Ionara Nay ma Gounes Passos (10 Examinadora)}

Doutora em Biotecnologia pela Rede Nordeste de Biotécnologia - RENORBIO

\section{Professor Ulisses Alves do Rego ( ${ }^{\circ}$ Examinador $)$}

Doutor em Ciências pelo Instituto de Química de São Carlos - IQSC/USP 


\section{DEDICATÓRIA}

A Deus, pela saúde, coragem, segurança e determinação que me concedeu durante toda minha trajetória neste curso.

Aos meus pais, Joel Soares Araújo e Rosilene Sousa Lima Araújo que estiveram comigo durante todo esse período de luta e por todo o amor, carinho, conselhos e cuidados. Aos meus irmãos, Ingryde Lima Araújo e Jessé Lima Araújo, por estarem sempre ao meu lado e pelas vibrações positivas.

A minha querida tia Liene Soares Pereira, pelos conselhos, carinho, amor, conforto e por tudo que fez por mim durante minha trajetória neste curso.

Ao meu orientador e amigo, Prof. Dr. Jefferson Almeida Rocha. Que além de um grande mestre se tornou um exemplo como pessoa e profissional, onde pretendo seguir seus passos. 


\section{AGRADECIMENTOS}

A Deus, primeiramente, por me conceder o dom da vida, a sabedoria e por me proteger nessa árdua caminhada.

A minha querida família que muito contribuísse para este momento, em especial aos meus pais, Joel Soares Araújo e Rosilene Sousa Lima e a minha querida tia, Liene Soares Pereira por suas contribuições no decorrer dessa minha trajetória acadêmica.

Aos meus amigos e amigas que estiveram comigo nos melhores e piores momentos no decorrer dessa caminhada, em especial Matheus Aires de Sousa, Lucas Aires de Sousa, Manuel Bruno Sousa Barros, Wanderson de Sousa Silva, Welson de Freitas Silva, José Venâncio Rodrigues Silva, Alice de Oliveira Sousa, Sabrina da Silva Ferreira, Ruan Sousa Bastos, Daniel Henrique Paulino de Arruda e por último e não menos importante a Família Tchoow, meu muito obrigado a todos vocês por fazerem parte de momentos difíceis e felizes durante minha trajetória neste curso.

Ao meu orientador que se tornou uma inspiração tanto como pessoa, quanto como profissional, onde se torna referência em minha continuidade no meio acadêmico e profissional.

Enfim, todos aqueles que contribuíram para o meu sucesso. 
"Tenha em mente que tudo que você aprendeu na escola é trabalho de muitas gerações (...) receba essa herança, honre-a, acrescente a ela e, um dia, finalmente, deposite-a nas mãos de seus filhos”. 


\section{RESUMO}

A leishmaniose é uma doença infecciosa crônica, ocasionada em humanos pela picada de um mosquito infectado classificado como flebotomíneo. Após a infecção, os parasitas metacíclicos de Leishmania, irão interagir principalmente com células fagocitárias que irão infectar e atingir os tecidos e órgãos, a depender da espécie de Leishmania e da interação imune e genética do hospedeiro. A L. major possui características únicas dentro do seu gênero, que a diferencia da $T$. brucei e $T$. cruzi metabolicamente. Além de terem características próprias dentro do seu genoma, também apresentam organelas particulares tais como os glicossomos, que funcionam como reservatórios de enzimas glicolíticas e cinetoplasto. A Química Quântica Computacional disponibiliza de dados algoritmos que nos permite localizar e decifrar estado de transição em transformações químicas nos fornecendo informações relevantes sobre interações moleculares de um potencial biológico, onde os resultados quânticos são de $95 \%$ de confiança. O presente trabalho tem como objetivo realizar testes de docking molecular e avaliação da atividade antileishmania in vitro de um complexo metálico de rutênio com epiisopiloturina e óxido nítrico $\left(\right.$ Epiruno $\left._{2}\right)$. As estruturas das proteínas em 3D dos alvos de L. major foram obtidas no banco de dados Protein Data Bank (PDB) com os códigos 1e7w (Pteridine reductase), 5nzg (UDP-glucose Pyrophosphorylase), 5g20 (Glycyl Peptide N-tetradecanoyltransferase), 5c7p (Nucleoside diphosphate kinase), 1ezr (Nucleoside hydrolase), 1lml (Leishmanolysin), 4ef8 (Dihydroorotate Dehydrogenase), 5142 (Pteridine reductase 1), 3ogz (UDP-sugar pyrophosphorylase), 3tue (Tryparedoxin peroxidase) e 2xe4 (Oligopeptidase B). Foi gerada uma caixa cúbica de 60 x 60 x 60 pontos com resolução de $0,35 \AA$ entre os pontos da grade para todo o alvo da proteína. Os centros das grades de afinidade molecular foram definidos a partir das coordenadas dos átomos dos seguintes resíduos Asn109, Lys380, Asn376, Gly91, Asp15, His264, Asn133, Arg287, Lys134, Thr49 e Arg83, respectivamente. Os resultados mais promissores de interação molecular foram alcançados nas espécies $5 \mathrm{nzg}$ e $1 \mathrm{e} 7 \mathrm{w}$, deste modo, o complexo Epiruno 2 demonstrou boa atividade biológica nos testes por docking molecular, demonstrando possuir melhor parâmetro de afinidade para os alvos $1 \mathrm{e} 7 \mathrm{w}$ e $5 \mathrm{nzg}$. Além desses dois alvos, constatouse que o complexo possui boa taxa de energia de interação molecular no sítio ativo das demais proteínas de Leishmania analisadas. Os ensaios in vitro, comprovam a atividade biológica do complexo Epiruno 2 em promastigotas de espécies de L. major com inibições de crescimento significativas, podendo concluir através de estudos in sílico por docking molecular e ensaios in vitro que o Epiruno 2 possui atividade antileishmania.

Palavras - chave: docking molecular; doenças negligenciadas; Leishmania major. 


\begin{abstract}
Leishmaniasis is a chronic infectious disease caused in humans by the bite of an infected mosquito classified as a sand fly. After infection, Leishmania metacyclic parasites will interact primarily with phagocytic cells that will infect and reach tissues and organs, depending on the Leishmania species and the host's immune and genetic interaction. The L. major has unique characteristics within its genus, which differentiates it from $\mathrm{T}$. brucei and $\mathrm{T}$. cruzi metabolically. In addition to having their own characteristics within their genome, they also have particular organelles such as glucosomes, which function as reservoirs of glycolytic and kinetoplast enzymes. Computational Quantum Chemistry provides data algorithms that allow us locate and decipher transition state in chemical transformations providing us with relevant information about molecular interactions of a biological potential, where quantum results are $95 \%$ reliable. The present work aims to perform molecular docking tests and evaluation of in vitro antileishmania activity of a ruthenium metal complex with epiisopiloturin and nitric oxide $\left(\right.$ Epiruno $\left._{2}\right)$. The 3D protein structures of L. major targets were obtained from the Protein Data Bank (PDB) database with codes 1e7w (Pteridine reductase), 5nzg (UDP-glucose Pyrophosphorylase), 5g20 (Glycyl Peptide N-tetradecanoyltransferase), 5c7p (Nucleoside diphosphate kinase), 1ezr (Nucleoside hydrolase), 11ml (Leishmanolysin), 4ef8 (Dihydroorotate Dehydrogenase), 5142 (Pteridine 3-phasease) sugar Tryparedoxin peroxidase) and 2xe4 (Oligopeptidase B). A 60 × $60 \times 60$ dot cubic box with $0.35 \AA$ resolution was generated between grid points for any protein target. The centers of the molecular affinity grids were defined from the atom coordinates of the following residues Asn109, Lys380, Asn376, Gly91, Asp15, His264, Asn133, Arg287, Lys134, Thr49 and Arg83, respectively. The most promising results of molecular interaction were achieved in species 5nzg and $1 \mathrm{e} 7 \mathrm{w}$, thus the Epiruno 2 complex showed good biological activity in molecular docking tests, demonstrating to have better affinity parameter for $1 \mathrm{e} 7 \mathrm{w}$ and $5 \mathrm{nzg}$ targets. In addition to these two targets, it was found that the complex has a good rate of molecular interaction energy at the active site of the other Leishmania proteins analyzed. The in vitro assays prove the biological activity of the Epiruno 2 complex in promastigotes of $\mathrm{L}$. major species with significant growth inhibitions. It can be concluded from molecular silica docking studies and in vitro assays that Epiruno $_{2}$ has antileishmania activity.
\end{abstract}

Key words: molecular docking; neglected diseases; Leishmania major. 


\section{LISTA DE FIGURAS}

Figura 01 Complexo metálico de rutênio com epiisopiloturina e óxido nítrico $\left(\right.$ Epiruno $\left._{2}\right)$

Figura 02 Docking molecular. Epiruno $2 / 1 \mathrm{e} 7 \mathrm{w}$ : a) ancoragem no sítio ativo do receptor, b) interação molecular entre o receptor e o ligante no sítio de ligação; Epiruno $_{2} / 5 \mathrm{nzg}$ : c) ancoragem no sítio ativo do receptor, b) interação molecular entre o receptor e o ligante no sítio de ligação.

Figura 03 Docking molecular. Epiruno $2 / 5 \mathrm{~g} 20$ : a) ancoragem no sítio ativo do receptor, b) interação molecular entre o receptor e o ligante no sítio de ligação; Epiruno $_{2} / 5 \mathrm{c} 7 \mathrm{p}$ : c) interação molecular entre o receptor e o ligante no sítio ativo; Epiruno 2 /lezr: d) ancoragem no sítio ativo do receptor, e) interação molecular entre $\mathrm{o}$ receptor e o ligante no sítio de ligação.

Figura 04 Docking molecular. Epiruno $2 / 1 \mathrm{lml}$ : a) ancoragem no sítio ativo do receptor, b) interação molecular entre o receptor e o ligante no sítio de ligação; Epiruno $_{2} / 4$ ef8: c) ancoragem no sítio ativo do receptor, d) interação molecular entre o receptor e o ligante no sítio de ligação; Epiruno $2 / 5142$ : e) ancoragem no sítio ativo do receptor, f) interação molecular entre o receptor e o ligante no sítio de ligação....

Figura 05 Docking molecular. Epiruno 2 /3ogz: a) ancoragem no sítio ativo do receptor, b) interação molecular entre o receptor e o ligante no sítio de ligação; Epiruno $_{2} / 3$ tue: c) ancoragem no sítio ativo do receptor, d) interação molecular entre o receptor e o ligante no sítio de ligação; Epiruno 2 /2xe4: e) interação molecular entre o receptor e o ligante no sítio de ligação

Figura 06 Média percentual de inibição do crescimento de promastigotas de L. major em presença do complexo metálico Epiruno 2 


\section{LISTA DE TABELAS}

Tabela 01 Códigos das enzimas depositadas no banco de dados do Prontein Data Bank (PDB) com o termo Leishmania major até o ano de 2018.

Tabela 02 Parâmetros de afinidade molecular do complexo metálico Epiruno 2 com proteínas de L. major.

24

Tabela 03 Valores de IC-50 de promastigotas de L. major em presença de um complexo metálico Epiruno 2 


\section{LISTA DE ABREVIATURAS E SIGLAS}

Epiruno $_{2}$ Complexo metálico de rutênio com epiisopiloturina e óxido nítrico

T. Cruzi Trypanosoma Cruzi

T. brucei Trypanossoma brucei

OMS Organização Mundial da Saúde

L. major Leishmania major

LTA Leishmaniose tegumentar americana

LV leishmaniose visceral

LCD leishmaniose cutânea disseminada

LCd Leishmaniose cutânea difusa

LM Leishmaniose mucosa

FIM fator inibitório de macrófagos

Anf. B Anfotericina B

EPI Epiisopiloturina

PDB Protein Data Bank

4ef8 Dihydroorotate Dehydrogenase

5g20 Glycyl Peptide N-tetradecanoyltransferase

5nzg UDP-glucose Pyrophosphorylase

$5142 \quad$ Pteridine reductase

$5 \mathrm{c} 7 \mathrm{p} \quad$ Nucleoside diphosphate kinase

3ogz UDP-sugar pyrophosphorylase

1e7w Pteridine reductase

1ezr Nucleoside hydrolase

$1 \mathrm{lml} \quad$ Leishmanolysin GP63

2xe4 Oligopeptidase B

3tue Tryparedoxin peroxidase

ADT Autodock Tools

AGL Algoritmo genético Lamarckiano

EUA Estados Unidos da América

SFB Soro fetal bovino

BOD Estufa de demanda biológica de oxigênio 
PTR1 A Pteridine reductase

DHB Biopterina a diidrobiopterina

THB 5,6,7,8-tetra-hidrobiopterina

SDR Redutase de cadeia curta

UTP Uridina trifosfato

Glc-1p Glicose-1-fosfato

NDKs Nucleoside diphosphate kinase

NTP Nucleosídeos trifosfatos

NDP Nucleosídeo difosfato

DHODH Dihidroorotate dehydrogenase

OPB Oligopeptidase B

IC50 Metade da concentração inibitória máxima 


\section{SUMÁRIO}

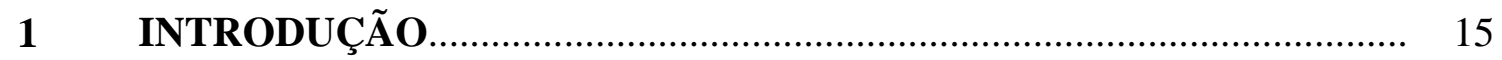

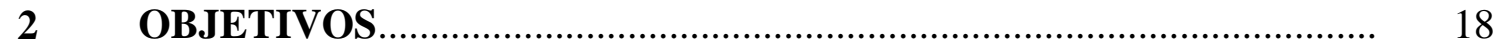

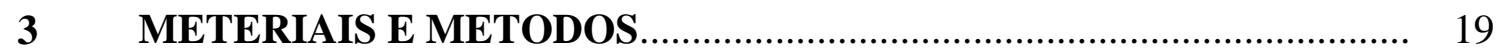

3.1 Prospecção de proteínas do PDB.......................................................... 19

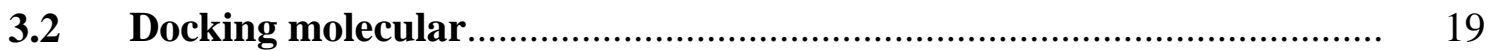

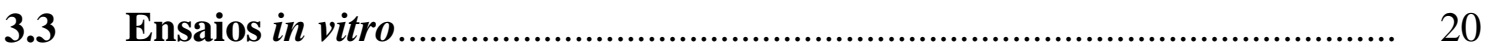

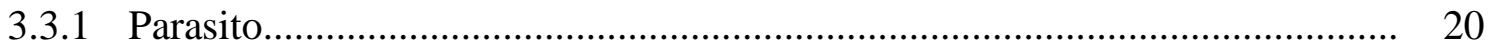

3.3.2 Atividade antileishmania de um complexo metálico de rutênio com epiisopiloturina e óxido nítrico em frações sobre formas promastigostas de L. major..................................................................................... 20

$4 \quad$ RESULTADOS E DISCUSSÃO

4.1 Prospecção de proteínas do PDB .......................................................... 21

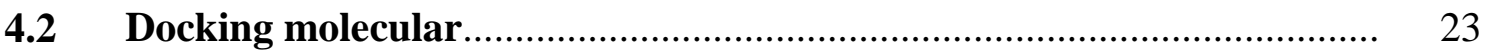

4.3 Ensaios in vitro da atividade antileishmania de um complexo metálico de rutênio com epiisopiloturina e óxido nítrico contra formas promastigotas de $L$. majo

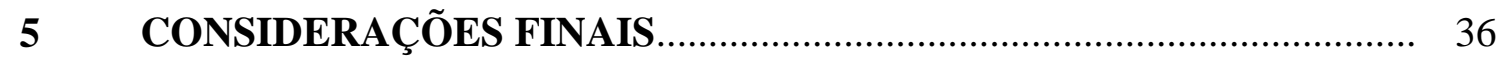

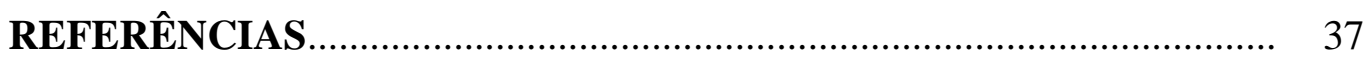




\section{INTRODUÇÃO}

Os tripanossomatídeos são uma família de protozoários uniflagelados que inclui parasitas dos gêneros Leishmania e Trypanosoma (PINTO et al., 2013). Estes agentes são responsáveis por ocasionar três tipos de doenças humanas: a tripanossomíase sul-americana (doenças de chagas) derivada pelo T. Cruzi; tripanossomíase africana ou doença do sono, causada por $T$. brucei; e a leishmaniose que agrega um conjunto de espécies. Essas três doenças são consideradas pela Organização Mundial da Saúde (OMS) como patologias negligenciadas, que atingem milhões de pessoas em países subdesenvolvidos, representando um problema de saúde pública e afetando a economia desses países em desenvolvimento (STUART et al., 2008).

A leishmaniose é uma doença que atinge mais de 98 países no mundo, sendo relatado cerca de 1,5 a 2 milhões de casos por ano, com uma taxa anual de 50 mil mortes (ALVAR et al., 2012). Há várias maneiras da doença se manifestar, podendo se apresentar de forma cutânea, mucocutânea e visceral. A infecção por espécies de leishmaniose do gênero de $L$. major possui evolução crônica, que acomete as estruturas da epiderme e cartilaginosas da nasofaringe de forma localizada ou difusa (SCOTT; NOVAIS, 2016).

O ciclo parasitário decorre da abundância de carboidratos na superfície de Leishmania, onde inclui lipofosfoglicanos, proteínas ancoradas a lipídeos glicosilfosfatidilinositol e proteofosfoglicanos (LLG, 2000). Essas glicoproteínas fazem parte do glicocálix da forma infecciosa promastigota, que é o processo mais importante na infectividade do hospedeiro (DESCOTEAUX; TURCO, 1999) e na interação flebotomínica (SACKS, 2001). Após a infecção, os parasitas metacíclicos de Leishmania irão interagir principalmente com células fagocitárias que irão infectar e atingir os tecidos e órgãos, a depender da espécie de leishmaniose e da interação imune e genética do hospedeiro. Essa infecção se apresenta de varias formas distintas, tais como a leishmaniose tegumentar americana (LTA) e a leishmaniose visceral (LV). A característica clinica apresentada da LTA em humanos são: cutânea disseminada (LCD); cutânea difusa (LCd); e mucosa (LM) (SAMPAIO; RIVITTI, 2008).

A L. major possui características únicas dentro do seu gênero, onde dois genes intimamente relacionados (lmjF33.1740 e LmjF33.1750) e cujas proteínas possuem domínio de fator inibitório de macrófagos (FIM) com cerca de 30 a $40 \%$ de identidade homologas de FIM. (MURRAY et al., 2005). Além de possuírem características próprias dentro do seu 
genoma, também apresentam organelas particulares tais como os glicossomos que funcionam como reservatórios de enzimas glicolíticas e cinetoplasto (IVES et al., 2005).

O tratamento da doença é composto por diversos fármacos como o antimonial pentavalente que é potencialmente tóxico e em muitos casos ineficaz, mas é o medicamento de primeira linha no tratamento de diversas espécies de leishmania. Além dos medicamentos de segunda linha como o AmBisomew, lipossomal, anfotericina B, miltefosina e a diamidinas (pentamidina) que também apresentam diversos efeitos colaterais as pessoas submetidas ao tratamento (CROFT; COOMBS, 2003; BRASIL, 2014).

Há décadas, pesquisadores desenvolvem novas formulações de fármacos e medicamentos alternativos em prol de um tratamento eficiente para esta doença, como: formulação tópica (RUIZ et al., 2014); nanoesferas (CARVALHO, 2013; LIMA, 2014); microemulsão (BUTANI et al., 2014); nanoemulsão (CALDEIRA et al., 2015); microtubos para liberação tópica (SALERNO et al., 2013) entre outros métodos já observados em diversos países (CROFT; SEIFERT, 2005).

A Química Quântica Computacional tem proporcionado diversas ferramentas que predizem propriedades moleculares relacionadas a um potencial farmacológico. Utilizando das leis da Química Quântica e de varias técnicas de programação que são capazes de prever estado de energia, estruturas moleculares, frequências vibracionais de sistemas atômicos e moleculares, propriedades moleculares. Pople et al., (1976), demonstra a utilidade de métodos computacionais para pesquisas de Química Quântica Computacional, pois elas geram informações cruciais a cerca das suas propriedades e estruturas moleculares. Algoritmos complexos são desenvolvidos para determinar as vibrações moleculares e espectro de infravermelho, desenvolvendo modelos virtuais economizando tempo e materiais que seriam desperdiçados em experimentos no laboratório (HEHRE et al., 1986; FIGUEIREDO, K.A et al., 2018).

Esta metodologia renovadora foi disponibilizada na década de 70 por Pople para a comunidade acadêmica. O programa computacional Gaussian-70 realiza diversos cálculos de propriedades moleculares, gerando resultados coerentes qualitativamente e quantitativamente com simulações experimentais, proporcionando confiança nos resultados (RAPPOPORT; FURCHE, 2010).

O complexo metálico de rutênio com epiisopiloturina e óxido nítrico (Epiruno ${ }_{2}$ ) (Figura 01) foi sintetizado a partir de um alcaloide pilocarpus, a Epiisopiloturina (EPI). A EPI é uma substância isolada da espécie Pilocarpus microphyllus Stapf, onde possui uma base isomérica ao invés do lado usual pilosina alcaloides, além da pilocarpina alcaloide principal. 
(VOIGTLANDER et al., 1978). Esta substância foi descoberta na década de 70, a partir de então, sua atividade biológica antiparasitária é estudada (GUIMARAES et al., 2014).

Considerando a presente literatura sobre atividade biológica do complexo de $\mathrm{Ru}$ (GARBIN et al., 2015) este trabalho tem como objetivo, estudos de docking molecular e avaliação da atividade antileishmania in vitro do complexo metálico de rutênio com epiisopiloturina e óxido nítrico.

Figura 01: Complexo Epiruno $_{2}$.

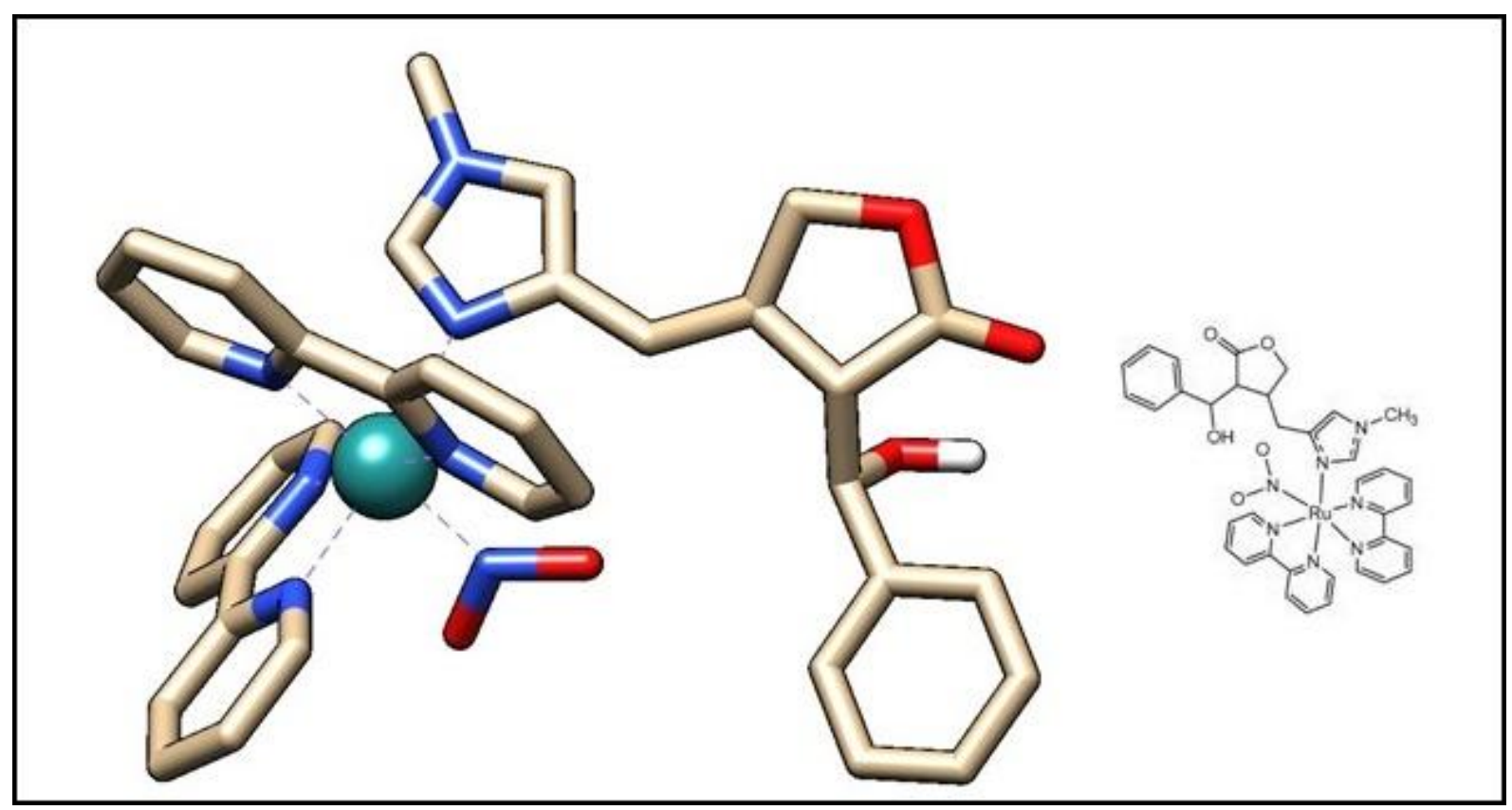




\section{OBJETIVOS}

\subsection{Geral:}

Docking molecular e avaliação da atividade anti-leishmania in vitro de um complexo metálico de rutêno com epiisopiloturina e óxido nítrico (Epiruno 2$)$.

\subsection{Específicos:}

- Realizar uma prospecção de proteínas de L. major no banco de dados do PDB.

- Determinar docking molecular no sítio ativo das proteínas de L. major pelo complexo metálico de rutênio com epiisopiloturina e óxido nítrico (Epiruno 2$)$;

- Analisar os efeitos do complexo metálico de rutênio com epiisopiloturina e óxido nítrico $\left(\right.$ Epiruno $\left._{2}\right)$ contra formas promastigotas de L. major. 


\section{MATERIAIS E METODOS}

\subsection{Prospecção de Proteínas do PDB}

Realizou-se uma busca de enzimas da espécie L. major, utilizando o banco de dados do Protein Data Bank (PDB) como predição para estudos antiparasitários. As estruturas tridimensionais dos principais alvos identificados foram obtidas no banco de dados PDB (http://www.rcsb.org/) (BERMAN et al., 2000). Essas enzimas vêm sendo cada vez mais utilizadas pelos cientistas em estudos in sílico, onde é possível determinar a interação molecular com substâncias bioativas, antecedentes a testes experimentais. O estudo prospectivo de proteínas de Leishmania serviu como base para testes de docking molecular e estudos de atividades biológicas, através de ensaios in vitro.

\subsection{Docking molecular}

As estruturas em 3D dos alvos de L. major foram obtidas no banco de dados de proteínas PDB com os códigos: 4ef8 (Dihydroorotate Dehydrogenase); 5g20 (Glycyl Peptide $\mathrm{N}$-tetradecanoyltransferase); 5nzg (UDP-glucose Pyrophosphorylase); 5142 (Pteridine reductase 1); 5c7p (Nucleoside diphosphate kinase); 3ogz (UDP-sugar pyrophosphorylase); 1e7w (Pteridine reductase); 1ezr (Nucleoside hydrolase); 11ml (Leishmanolysin GP63); 2xe4 (Oligopeptidase B); e 3tue (Tryparedoxin peroxidase). Os docking's foram realizadas utilizando o programa Autodock Tools (ADT) (http://autodock.scripps.edu/), versão 1.5.6 (GOODSELL; MORRIS, 1996; GOODSELL, 2005; MORRIS et al., 2008). Em seguida, os arquivos de proteínas foram preparados pela remoção de todas as moléculas de água e outros grupos, como íons, usando o software CHIMERA v.13.1 (https://www.cgl.ucsf.edu/chimera/) (PETTERSEN et al., 2004).

As proteínas e ligantes foram preparadas com a remoção de todas as moléculas de água e outros grupos, como íons usando o software CHIMERA v.13.1 (PETTERSEN EF et al., 2004). O receptor foi considerado rígido, enquanto que cada ligante foi considerado flexível. As cargas parciais Gasteiger (GASTEIGER \& MARSILI, 1980) foram calculadas após a adição de todos os hidrogênios. Os átomos de hidrogênio não polares de proteínas e ligantes foram subsequentemente mesclados. Foi gerada uma caixa cúbica de 60 x 60 x 60 pontos com resolução de $0,35 \AA$ entre os pontos da grade para todo o alvo da proteína. Os centros das grades de afinidade molecular foram definidos a partir das coordenadas dos 
átomos dos resíduos Asn133, Asn376, Lys380, Arg287, Gly91, Lys134, Asn109, Asp15, His264, Arg83 e Thr49 respectivamente.

O algoritmo genético Lamarckiano (AGL) com busca global (MORRIS et al., 1998) e pseudo-Solis e Wets com busca local (SOLIS, 1981) foram os métodos utilizados na docking molecular. Cada simulação consistiu de 100 corridas independentes (RAMOS et al., 2012). O restante dos parâmetros do docking molecular foi definido com os valores padrões. As análises foram concentradas nos grupos de menor energia. A conformação de menor energia combinada com inspeção visual foi escolhida para uma análise mais detalhada (ROCHA et al., 2018).

\subsection{Ensaios in vitro}

\subsubsection{Parasitos}

Foram utilizadas cepas da espécie L. major MHOM/IL/80/Friedlin mantidas no Laboratório de Atividade Antileishmania, localizado no Núcleo de Pesquisas em Plantas Medicinais da Universidade Federal do Piaú e cultivados em meios Schneider's (Sigma, EUA), suplementado com $10 \%$ de soro fetal bovino (SFB) (Sigma, EUA e penicilinaestreptomicina $10.000 \mathrm{UI} / 10 \mathrm{mg}$ (Sigma, EUA) a $26{ }^{\circ} \mathrm{C}$ em estufa de demanda biológica de oxigênio (BOD).

\subsubsection{Atividade antileishmania de um complexo metálico de rutênio com epiisopiloturina e óxido nítrico em frações sobre formas promastigotas de $L$. major.}

Formas promastigotas em fase logarítmica de crescimento foram semeadas na quantidade $1 \times 10^{6}$ parasitas por poço, em microplaca de cultivo celular de 96 poços, contendo meio Schneider's suplementado e a substância em diluição seriada, atingindo as concentrações de 800 a 6,25 $\mu \mathrm{g} / \mathrm{mL}$. As placas foram incubadas em estufa BOD a temperatura de $26{ }^{\circ} \mathrm{C}$. Após $48 \mathrm{~h}$ foi adicionado resazurina $(1 \mathrm{mM})$ e incubou-se novamente a placa por 6h. Após, foi realizada a leitura em espectofotômetro para obtenção da densidade ótica a 550 $\mathrm{nm}$. O controle negativo foi realizado com meio Schneider's a 0,2\% de DMSO e considerado como $100 \%$ de viabilidade dos parasitos. Anf. B na concentração de $2 \mu \mathrm{g} / \mathrm{mL}$ foi utilizada como controle positivo para validação do experimento (CARNEIRO et al., 2012). 


\section{RESULTADOS E DISCUSSÃO}

\subsection{Prospecção de Proteínas do PDB}

As enzimas e respectivos códigos prospectadas de L. Major foram inseridas na Tabela 01. Foram encontrados no banco de dados do PDB, 180 códigos de identificação e 66 proteínas desta espécie.

Tabela 01: Códigos das enzimas depositadas no banco de dados do PDB com o termo $L$. major até o ano de 2018.

\begin{tabular}{|c|c|}
\hline Enzimas & Identificação PDB \\
\hline Adenosylhmocysteinase & $3 \mathrm{G} 1 \mathrm{U}$ \\
\hline ADP-Ribosylationfactor & $2 \times X 77$ \\
\hline Ap- Endocuclease & $2 \mathrm{~J} 63$ \\
\hline Ascorbate peroxidase & $\begin{array}{c}\text { 5AMM, 5AL9, 5ALA, 4GED, 4GED, } \\
\text { 3RIV, 3RIW }\end{array}$ \\
\hline Aspartateaminotransferase & $4 \mathrm{H} 51$ \\
\hline Coproporphyrinogen III oxidase & 3DWR, 3DWS, 2QT8, 1VJU \\
\hline Cytochrome c & 4DY9 \\
\hline Cysteinesynthase & 4AIR \\
\hline Class I phospodiesterase PDEB1 & 2R8Q \\
\hline Dihydroorotatedehydrogenase & $\begin{array}{c}\text { 4EF8, 4EF9, 3TJX, 3TRO, 3TQ0, } \\
\text { 3MHU, 3MJY, 3GZ3, 3GYE }\end{array}$ \\
\hline Dutpase & 2YAY, 2YAZ, 2YB0, 2CJE \\
\hline Glycylpeptide n-tetradecanoyltransferase & $\begin{array}{c}\text { 5G20, 5G21, 5A27, 5A28, 5AG4, } \\
\text { 5AG5, 5AG6, 5AG7, 5AGE, 4UCM, } \\
\text { 4UCN, 4UCP, 4CYP, 4CYN, 4CYO, } \\
\text { 4CYQ, 4C7H, 4C7I, 4CGL, 4CGM, } \\
\text { 4CGN, 4CGO, 4CGP, 4A2Z, 4A30, } \\
\text { 4A31, 4A32, 4A33, 2WSA, 3H5Z }\end{array}$ \\
\hline UDP-glucose pyrophosphorylase & $\begin{array}{c}\text { 5NZG, 5NZH, 5NZI, 5NZJ, 5NZK, } \\
\text { 5NZL, 5NZM, 4J18, 4M28, 4M2A, } \\
\text { 4M2B, 2OEF, 2OEG }\end{array}$ \\
\hline Peptidyl-prolylci-transisomerase & 2HQJ \\
\hline
\end{tabular}


Possible 3-mercaptopyruvate Sulfurtransferase

Proteintyrosinephosphatase-likeProtein

Pteridinereductase 1

Prostaglandin f2-alpha synthase

ProbableUbiquitinfoldmodifierConjugatingenzyme

Proteinkinase, putativeGlycogenSynthasekinase

Putative C-1-tetrahydrofolate Synthase, cytoplasmic

Putativeeukaryotictranslationinitiationfactor

Putativephosphoglucomutase

Putativeprolyl-tRNAsynthetase

Putativeselenophosphate

Putativeaminopeptidase

Putativeuncharacterizedprotein

Pseudoperoxidase

Pteridinereductase

ProbableeukaryoticD-aminoAcidtRNAdeacylase,

LMAJ005534AAA

Ribonuclease MAR1

Tyrosyl-tRNAsynthetase

Thymidinekinase

Tubulinbindingcofactor

Trypanothionesynthetase

Tryparedoxin peroxidase

Threonineoldolase

Trypanothione-dependentglyxalase I

FBP protein

Fumaratehydratase

Farnesylpyrophosphatesynthase

Integron gene cassetteprotein

Macrophagemigrationinhibitory
$1 \mathrm{OKG}$

$3 \mathrm{~S} 4 \mathrm{O}$

5L42, 5L4N, 3H4V, 2QHX, 2BF7,

2BFA, 2BFM, 2BFO, 2BFP, 1W0C,

1E92, 1E7W

4G5D, 4F40

3KPA

3E3P

$4 \mathrm{~A} 26$

5WB5, 5WB5

4QG5

5XIL

5L16

$5 \mathrm{NTH}$

3M3I

5VIA

1W0C, 1E7W

$1 \mathrm{TC} 5$

1XN4

3POH, 3POI, 3POJ

4UXH, 4UXI, 4UXJ

5AJ8, 4CQI

2VOB, 2VPM, 2VPS

4K1F, 3TUE, 2S9F

1SVV

$2 \mathrm{C} 21$

5OEY, 5OEZ, 5OFU

5L2R

4K10, 4JZX, 4JZB

4NWR

3FWU, 3FWT, 3B64 
Malatedehydrogenase

MSE Ouervon MSE

Mix 1

Methionyl-tRNAsythetase

Mevalonatekinase, putative

Mitogen-activatedproteinkinase

Nucleosidediphosphatekinase

Nucleosidehydrolase

Oligopeptidase B

SB(V)-AS(V) Reductase

SAS-6

Superoxide dismutase

UTP-glucose-1-phosphate uridylytransferase 2

UDP-sugar pyrophosphorylase

Uncharacterizelprotein

Ubiquitin Carrier protein 4

Heatshockprotein 83-1

Hypotheticalprotein

Initiationfactor 2B

Leishmania Major Homologofprogrammedcell

Leishmanolysin

Lmaj004091AAA
4H7P

$3 \mathrm{LJN}$

3HA4

$3 \mathrm{KFL}$

2HFS, $2 \mathrm{HFU}$

3UIB, 3PG1

5C7P,5CAA, 5CAB, 3NGR, 3NGS, 3NGT, 3NGU

1EZR

2XE4

$2 \mathrm{~J} 6 \mathrm{P}$

4CKM, 4CKP

$4 \mathrm{~F} 2 \mathrm{~N}$

2OEF, 2OEG

3OGZ, 3OH0, 3OH1, 3OH2, 3OH3,

$3 \mathrm{OH} 4$

5IJM, 3KSV

1YF9

3U67, 3Q5J, 3Q5K, 3Q5L, 3HJC, 3H80

2AR1, 1R75, 2B4W, 1YQF

$2 \mathrm{~A} 0 \mathrm{U}$

1Y1X

1LML

1XTP, 1Y63

\subsection{Docking molecular}

Os critérios de avaliação foram definidos pelos resultados de ligações de hidrogênio, ligações hidrofóbicas e menor energia de ligação. Com base nesses critérios, foram escolhidos os alvos que possuem maiores afinidades moleculares com o complexo Epiruno 2 para ensaios biológicos. Todos os resultados de docking molecular estão disponíveis na Tabela 02. 
Tabela 02: Parâmetros de afinidade molecular do complexo metálico Epiruno 2 com proteínas de L. major.

\begin{tabular}{|c|c|c|c|c|c|c|}
\hline $\begin{array}{l}\text { Complexo } \\
\text { (proteína- } \\
\text { ligante) }\end{array}$ & $\begin{array}{r}\Delta \mathbf{G}_{\text {bind }}{ }^{\mathbf{a}} \\
\left(\text { kcal }^{-1}\right. \\
\left.\text { mol }^{-1}\right)\end{array}$ & $\mathbf{K i}^{\mathbf{b}}(\boldsymbol{\mu M})$ & $\begin{array}{c}\text { Número de } \\
\text { Corridas } \\
\text { de Encaixe } \\
\text { Independe } \\
\text { ntes } \\
\end{array}$ & $\begin{array}{l}\text { Número de } \\
\text { Conformações } \\
\text { no Primeiro } \\
\text { Cluster }\end{array}$ & $\begin{array}{c}\text { Aminoácidos } \\
\text { que Interagem } \\
\text { Através de } \\
\text { Ligações de } \\
\text { Hidrogênio } \\
\end{array}$ & Aminoácidos que Fazem Interações Hidrofóbicas \\
\hline Epiruno $_{2} / 1 \mathrm{e} 7 \mathrm{w}$ & $-10,68$ & $14,8 \mathrm{nM}$ & 100 & 7 & $\begin{array}{l}\text { Asp232, Lys198, } \\
\text { Ser111, Ser227 }\end{array}$ & $\begin{array}{c}\text { Arg17, Asn109, Asp181, Gly225, Leu18, Leu188, } \\
\text { Leu226, Leu229, Met179, Met233, Phe113, Pro224, } \\
\text { Tyr194, Val180, Val228 }\end{array}$ \\
\hline Epiruno $_{2} / 5 \mathrm{nzg}$ & $-10,51$ & $19,74 \mathrm{nM}$ & 100 & 6 & $\begin{array}{l}\text { Asp221, Gly220, } \\
\text { Lys95 }\end{array}$ & $\begin{array}{c}\text { Ala355, Asn219, Asn82, Glu190, Glu284, Glu353, } \\
\text { Gly256, Gly84, His191, Leu81, Lys380, Ser285, Thr354, } \\
\text { Thr96 }\end{array}$ \\
\hline Epiruno $_{2} / 5 \mathrm{~g} 20$ & $-9,65$ & $83,81 \mathrm{nM}$ & 100 & 81 & 0 & $\begin{array}{c}\text { Ala343, Arg231, Asn376, Asp83, Gly397, His219, } \\
\text { Leu227, Leu341, Phe88, Phe90, Ser221, Ser330, Tyr217, } \\
\text { Tyr345, Val374 }\end{array}$ \\
\hline Epiruno $_{2} / 5 c 7 p$ & $-8,22$ & $935,7 \mathrm{nM}$ & 100 & 43 & $\begin{array}{l}\text { Arg104, Asn114, } \\
\text { Ser98 }\end{array}$ & $\begin{array}{l}\text { Ala108, Arg87, Asp110, Asp97, His117, Leu54, Leu63, } \\
\text { Lys11, Phe59, Tyr51, Val109, Val111 }\end{array}$ \\
\hline Epiruno $_{2} / 1$ ezr & $-8,19$ & $996,06 \mathrm{nM}$ & 100 & 4 & Pro11, gln40 & $\begin{array}{l}\text { Asn168, Asn39, Asp10, Asp14, Asp15, Asp241, Glu166, } \\
\text { Gly12, His240, Met152, Phe167, Tyr225, Tyr229, Val45 }\end{array}$ \\
\hline Epiruno $_{2} / 11 \mathrm{lml}$ & $-8,05$ & $1,26 \mu \mathrm{M}$ & 100 & 8 & $\begin{array}{l}\text { Glu265, His264, } \\
\text { His268, His334 }\end{array}$ & $\begin{array}{c}\text { Ala225, Ala346, Ala348, Ala349, Glu221, Gly222, } \\
\text { Gly329, Leu224, Phe451, Pro347, Ser330, Val223, } \\
\text { Val261 }\end{array}$ \\
\hline Epiruno $_{2} / 4 \mathrm{ef} 8$ & $-7,73$ & $2,17 \mu \mathrm{M}$ & 100 & 7 & Arg105, Asn133 & $\begin{array}{l}\text { Ala146, Asn107, Cys131, Cys150, Gln149, Gly101, } \\
\text { Leu102, Met104, Pro132, Ser103, Val134, Val140 }\end{array}$ \\
\hline Epiruno $_{2} / 5142$ & $-7,62$ & $2,6 \mu \mathrm{M}$ & 100 & 7 & Lys 244 & $\begin{array}{l}\text { Ala288, Arg287, Gln186, His241, Leu188, Leu189, } \\
\text { Pro187, Thr286, Tyr283 }\end{array}$ \\
\hline Epiruno $_{2} / 3$ ogz & $-6,71$ & $12,16 \mu \mathrm{M}$ & 100 & 5 & Lys134 & $\begin{array}{c}\text { Arg127, Asp271, Gln270, Glu126, Gly122, Gly123, } \\
\text { His224, Leu124, Leu128, Val120 }\end{array}$ \\
\hline Epiruno $_{2} / 3$ tue & $-6,58$ & $14,91 \mu \mathrm{M}$ & 100 & 27 & $\begin{array}{l}\text { Asp47, Phe50, } \\
\text { Val51 }\end{array}$ & Arg128, Leu46, Met147, Phe48, Pro45, Thr49 \\
\hline Epiruno $_{2} / 2 \mathrm{xe} 4$ & $-6,12$ & $32,8 \mu \mathrm{M}$ & 100 & 1 & $\begin{array}{l}\text { Ala80, Asp78, } \\
\text { Leu82 }\end{array}$ & Ala77, Asp78, Gln81, Ile79, Lys719, Thr724 \\
\hline
\end{tabular}


A Pteridine reductase (PTR1) $(1 \mathrm{e} 7 \mathrm{w})$, exerce uma função de reduzir pterinas conjugadas e não conjugadas, um exemplo é a biopterina a diidrobiopterina (DHB), em seguida a 5,6,7,8-tetra-hidrobiopterina (THB) ou de folato a DHF e THF. Ela é a única proteína conhecida por reduzir a biopterina em Leishmania, mostrando ser essencial para o crescimento in vivo através de estudos knockout genéticos (NARE; HAEDY e BEVERLEY, 1997). A PTR1 possui em sua estrutura 288 resíduos que contém um único domínio $\alpha / \beta$ com topológica típica de redutase de cadeia curta (SDR) baseada na dobra de Rossmann (TANAKA et al., 1996). O docking molecular do complexo $1 \mathrm{e} 7 \mathrm{w} /$ Epiruno $_{2}$ obteve a menor energia de ligação dentre as docagens realizadas neste estudo, com uma taxa de -10.68 Kcal.mol $^{-1}$ e uma constante de inibição de 14,8 nM. Essa energia de ligação indica uma potente interação entre a macromolécula e o ligante, podendo observar fortes interações moleculares nas quatro pontes de hidrogênio ligadas aos aminoácidos Asp232, Lys198, Ser111 e Ser227, locais em que agem as maiores forças intermoleculares (Tabela 02). Os aminoácidos Arg17, Asp181, Asp232, Leu18, Leu188, Leu226, Leu229, Lys198, Met179, Met233, Phe113, Pro224, Ser227, Val180, Val228 realizam as interações hidrofóbicas (Tabela 02). A imagem ilustrativa da docking molecular entre o Epiruno $2 / 1 \mathrm{e} 7 \mathrm{w}$ está disponível na Figura 02.

O acoplamento molecular da UDP-glucose Pyrophosphorylase (5nzg) obteve uma energia de ligação de $-10,51 \mathrm{Kcal}_{\mathrm{mol}}{ }^{-1}$ que também possui uma potente interação entre o receptor e o ligante. Isso pode está relacionado à UGP, que catalisa a síntese da forma ativada de glicose, UDP-Glc, de uridina trifosfato (UTP) e glicose-1-fosfato (Glc-1p). Como a reação de UDP-Glc é fundamental na produção de carboidratos, como glicanos de superfície celular e outros processos de organismos patogênicos (FÜ HRING et al., 2013) se tornam alvos atrativos em estudos de inibição molecular (LAMERZ et al., 2006). A Ki foi de 19,74 nM, nos mostrando a forte atividade biológica da Epiruno 2 em reação com a UDP. Isso nos indica a alta interação molecular entre ligante e macromolécula e tal afinidade molecular pode ser comprovada com a formação de três pontes de hidrogênios nos aminoácidos, Asp211, Gly220, Lys95 (Tabela 02), onde a força intermolecular entre a proteína 5nzg e a Epiruno 2 são mais intensas. Os aminoácidos Ala355, Asn82, Asn219, Glu284, Glu353, Gly84, Gly256, His191, Lys380, Ser285, Thr96 e Thr354 realizam as interações hidrofóbicas (Tabela 02). A imagem ilustrativa da docking molecular entre o complexo Epiruno $2 / 5 \mathrm{nzg}$ está disponível na Figura 02. 
Figura 02: Docking molecular. Epiruno $2 / 1 \mathrm{e} 7 \mathrm{w}$ : a) ancoragem no sítio ativo do receptor, b) interação molecular entre o receptor e o ligante no sítio de ligação; Epiruno $2 / 5 \mathrm{nzg}$ : c) ancoragem no sítio ativo do receptor, d) interação molecular entre o receptor e o ligante no sítio de ligação.

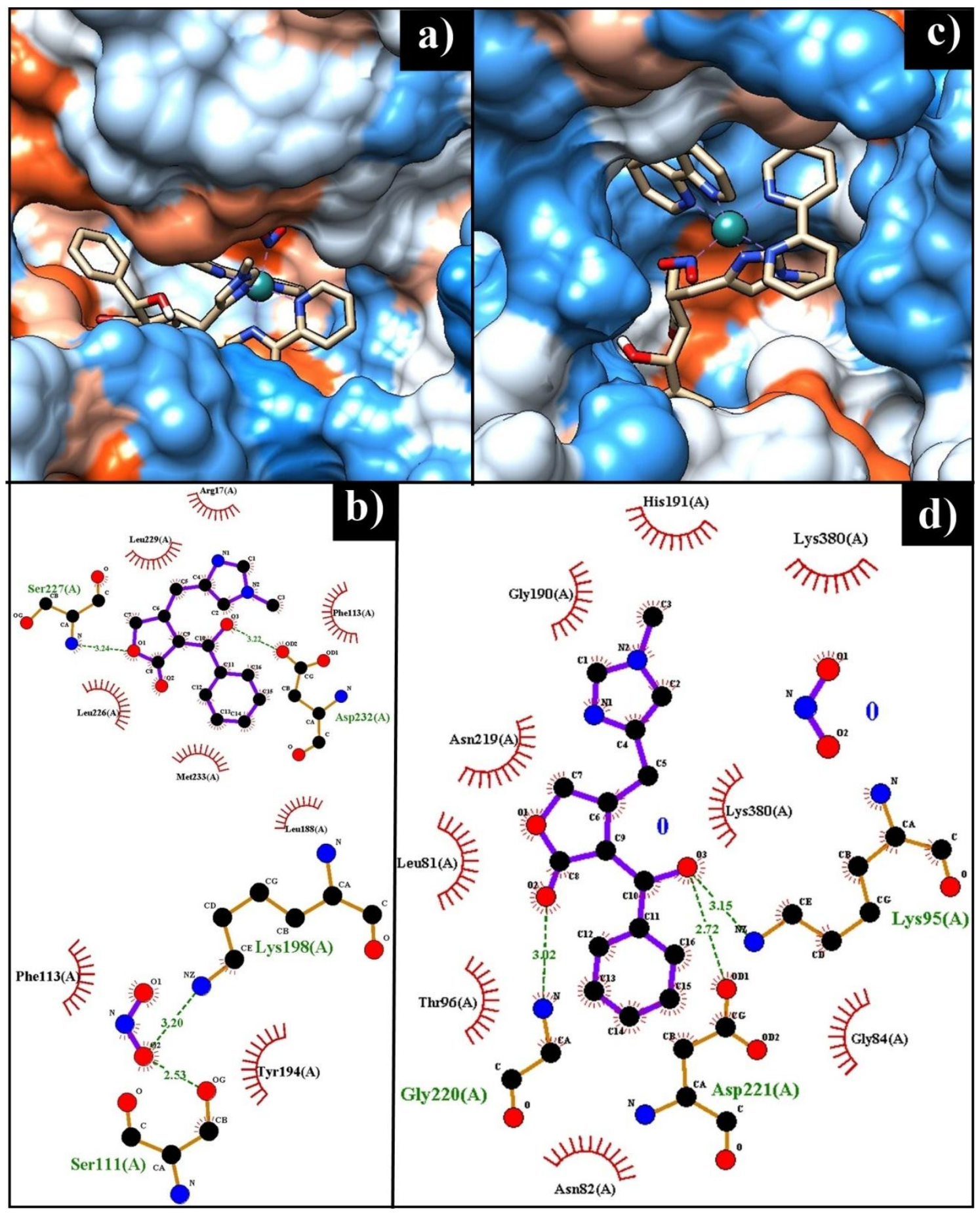

A interação molecular entre a Epiruno 2 com a proteína Glycyl Peptide Ntetradecanoyltransferase ( $5 \mathrm{~g} 20$ ) obteve uma importante energia de ligação de $-9,65 \mathrm{Kcal} \mathrm{mol}^{-1}$ e uma constante de inibição de 83,81 nM. O complexo não obteve nenhuma interação por ligação de hidrogênio em nenhum dos aminoácidos (Tabela 02). Os aminoácidos Ala343, 
Arg231, Asn376, Asp83, Gly397, His219, Leu227, Leu341, Phe88, Phe90, Ser221, Tyr217, Tyr345 e Val374 fazem as interações hidrofóbicas (Tabela 02). A N-tetradecanoyltransferase cumpre a função de selecionar a transferência da cadeia de ácido graxo $\mathrm{C}_{14}$ de misistoil coenzima (A) para resíduos de glicina N-terminal de proteínas substrato (JOHNSON et al., 1994). Essa modificação desempenha uma função central em variedade de processos celulares, como coordenadas de ancoragem reversível de proteínas a membranas (WRIGHT et al., 2010). A estabilidade da estrutura terciária faz parte de elementos de reconhecimento que facilitam nas interações moleculares entre a proteína e o ligante (CHOW et al., 1987). A imagem ilustrativa da interação molecular entre o complexo Epiruno $2 / 5 \mathrm{~g} 20$ está disponível na Figura 03.

As Nucleoside diphosphate kinase (NDKs; EC 2.7.4.6) são proteínas importantes e indispensáveis para a manutenção dos níveis intracelulares de nucleosídeos trifosfatos (NTP). Eles transportam o grupo $\gamma$-fosforil de uma NTP para um nucleosídeo difosfato (NDP) através de um esquema funcional denominado como ping-pong que envolve a fosfohistidina intermediária covalente. Os NDKs eucarióticos são compostos por subunidades de 15 a 18 KDA com semelhanças em suas estruturas gerais e um sítio ativo conservado (LASCU E GONIN, 2000; SOUZA et al., 2011). A estrutura de Leishmania Nucleoside diphosphate kinase $(5 c 7 p)$ ancorada ao ligante Epiruno 2 obteve uma energia de ligação de -8,22 Kcal.mol ${ }^{-1}$ e uma constante de inibição de 935,7 nM. O complexo formou três ligações de hidrogênio nos aminoácidos Arg104, Asn114 e Ser98 que interagem com maior força intermolecular nas moléculas (Tabela 02). Os aminoácidos Ala108, Arg87, Arg104, Asp110, His117, Leu63, Lys11, Phe59, Ser98, Val109 e Val111 fazem as interações hidrofóbicas (Tabela 02). A imagem ilustrativa do acoplamento molecular entre o complexo Epiruno $2 / 5 c 7 p$ está disponível na Figura 03.

A Nucleoside Hydrolase pode ser identificada em extratos livres de células do parasita de Leishmania, onde também há existência de nucleoside hydrolase em diversos protozoários parasitários, ela se caracteriza por ser uma enzima útil em infecções parasitarias (PARKIN et al., 1997). A nucleoside hydrolase mais abundante em células, é a IU1- nucleoside hydrolase, ela catalisa a hidrólise eficiente de ambos os nucleosidos de purina e pirimidina (PARKIN et al., 1991). A sua inibição é fundamental para o tratamento de L. major, onde a busca por novos compostos bioativos é fundamental (BERMAN et al., 1996; CROFT et al., 1997). O Epiruno $_{2}$ apresentou forte interação molecular com a Nucleoside hydrolase de L. major (1ezr), obtendo uma energia de ligação de $-8,19 \mathrm{Kcal} \mathrm{mol}^{-1}$ e uma constante de inibição de 996,06 nM. As interações de menor energia acontecem nos resíduos Pro11 e Gln40, as duas pontes de 
hidrogênio geradas (Tabela 02). Os aminoácidos Asn39, Asp10, Asp14, Asp15, Asp241, Gly12, His240, Met152, Phe167, Tyr225, Val45 fazem as interações hidrofóbicas (Tabela 02). A imagem ilustrativa da docking molecular entre o complexo Epiruno $2 / 1$ ezr está disponível na Figura 03.

Figura 03: Docking molecular. Epiruno $2 / 5 \mathrm{~g} 20$ : a) ancoragem no sítio ativo do receptor, b) interação molecular entre o receptor e o ligante no sítio de ligação; Epiruno $2 / 5 \mathrm{c} 7 \mathrm{p}$ : c) interação molecular entre o receptor e o ligante no sítio ativo; Epiruno $2 / 1$ ezr: d) ancoragem no sítio ativo do receptor, e) interação molecular entre o receptor e o ligante no sítio de ligação.

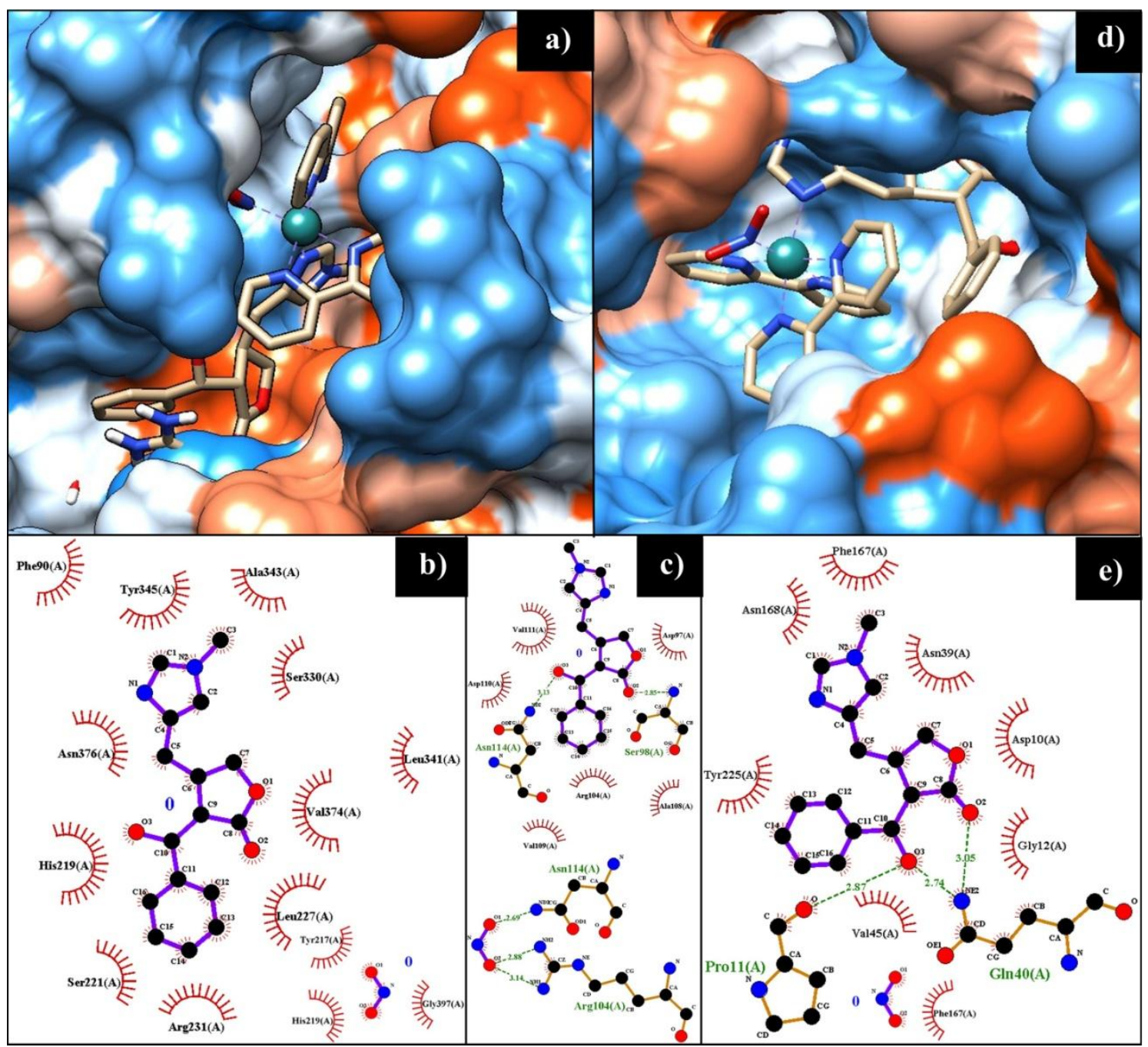

A glicoproteína GP63 ou leishmanolisina (1lml) representa mais de 1\% da proteína total do parasito (JAFFE; DWYER, 2003). Tendo em vista que a $1 \mathrm{lml}$ é uma metaloprotease que predomina grupos funcionais em seu sítio ativo, torna-se um alvo muito interessante em estudos de docking molecular como uma alternativa para surgimento de novos fármacos. $\mathrm{O}$ docking molecular entre o complexo Epiruno $_{2} / 1 \mathrm{lml}$, resultou em uma forte interação molecular, com uma energia de ligação de $-8,05 \mathrm{Kcal} \mathrm{mol}^{-1}$ e uma constante de inibição de 
1,26 $\mu$ M. O complexo formou quatro pontes de hidrogênio nos aminoácidos Glu265, His264, His268 e His334, onde destacamos que além da ótima interação molecular entre as moléculas, existem quatro ligações onde agem as maiores forças intermoleculares, que são os locais de ligações mais intensas (Tabela 02). Os aminoácidos Ala348, Glu221, Glu265, Gly222, Phe451, Pro347, Val223, Val261 realizam as interações hidrofóbicas (Tabela 02). A imagem ilustrativa do docking molecular está disponível na Figura 04.

A Dihidroorotate dehydrogenase (DHODH) possui poucos análogos de pirimidina como inibidores baseado em substrato que ligam ao sítio ativo de diidroorotato (DEFREES et al., 1988). Os inibidores conhecidos são ligados a DHODH de classe dois, que são ligadas em um cofator de ubiquinina (VYAS; GHAT, 2011). A maioria dos inibidores de DHODH de classe 2, não é eficaz contra a DHODH de classe 1A, já que seu sítio de ligação é a quinona. Esses inibidores específicos apenas agem especificamente o DHODH de classe 1A Lactococcus lactis (PALFEY; BJORNBERG; JENSEN, 2001) e T. brucei (ARAKAKI et al., 2008) e análogos de orotato que apresenta inibição contra T. cruzi e L. major (CHELESKI et al., 2010).

$\mathrm{A} \mathrm{Epiruno}_{2}$ apresentou bons resultados in sílico por docking molecular, mostrando que possui atividade biológica contra a DHODH de L. major (4ef8) de classe 1A, obtendo uma constante de inibição de 2,17 $\mu \mathrm{M}$, e uma energia de ligação de $-7,73 \mathrm{Kcal} \mathrm{mol}^{-1}$. A interação mais eletronegativa acontece nos aminoácidos Arg105 e Asn133, onde são localizadas as pontes de hidrogênio, locais de maiores forças intermoleculares entre o DHODH de L. major

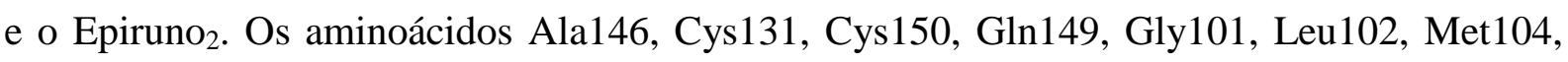
Pro132, Ser103, Val134 e Val140 fazem as interações hidrofóbicas (Tabela 02). A imagem ilustrativa do docking molecular entre o complexo Epiruno $/ 4$ ef8 está disponível na Figura 04.

O docking molecular do complexo Epiruno 2 e a proteína Pteridine reductase 1 de $L$. major (LmPTR1) obteve uma energia de ligação de -7,62 Kcal.mol ${ }^{-1}$ e uma constante de inibição de 2,6 $\mu \mathrm{M}$. O complexo formou uma ligação de hidrogênio no aminoácido Lys244 (Tabela 02), local onde a força intermolecular do complexo é mais intensa. Os aminoácidos Ala288, His241, Leu188, Leu189, Pro187 e Thr286 fazem as interações hidrofóbicas (Tabela 02). A PTR1 é um alvo atrativo para descobertas de drogas antitrypanosomal e antileishmanial. A literatura mostra diferentes arcabouços, como pteridina, pirrolopirimidina e benzimidazol, onde relata que a ligação inibitória da atividade da PTR1 é no biopterina (CAVAZZUTI et al., 2008; TULLOCH et al., 2009; MPAMHANGA et al., 2009; KHALAF 
et al., 2014). A imagem ilustrativa do docking molecular entre a Epiruno $2 / 5142$ está disponível na Figura 04.

Figura 04: Docking molecular. Epiruno $2 / 1 \mathrm{lml}$ : a) ancoragem no sítio ativo do receptor, b) interação molecular entre o receptor e o ligante no sítio de ligação; Epiruno $2 / 4$ ef8: c) ancoragem no sítio ativo do receptor, d) interação molecular entre o receptor e o ligante no sítio de ligação; Epiruno $2 / 5142$ : e) ancoragem no sítio ativo do receptor, f) interação molecular entre o receptor e o ligante no sítio de ligação.

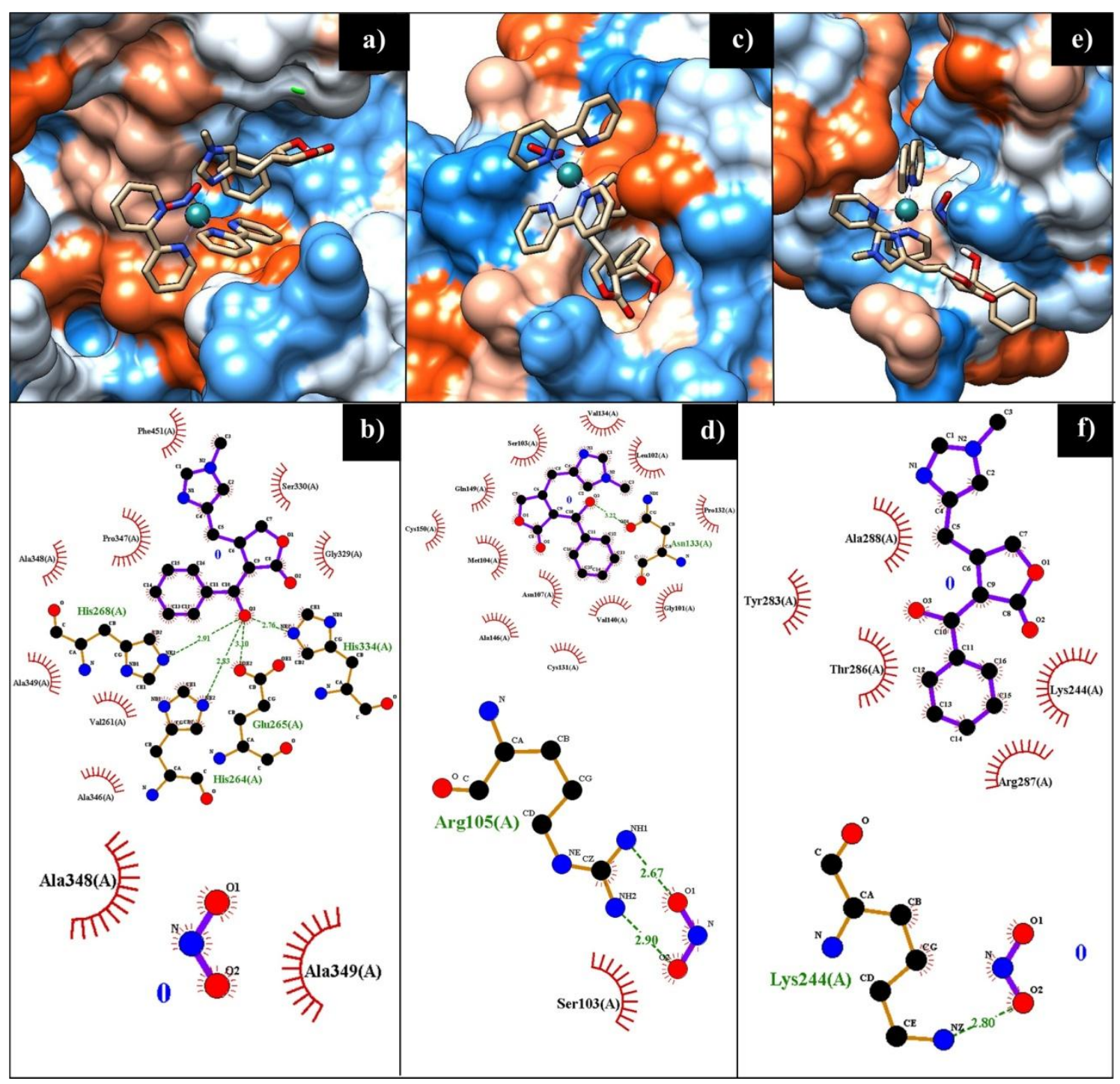

A proteína USP é o homólogo de artrópodes do receptor $\mathrm{X}$ retinóide de vertebrados (RXR $\alpha, \beta, \mathrm{y}$; NR2B1, 2, 3), vertebrados, moluscos e cnidários (LAUDET e GRONEMEYER, 2002). A USP também é uma proteína especialista em diferentes tipos de ligações ao DNA classificada como heterodimerização, que é uni presente para NRs classe II (BRELIVET el al., 2004). Em L. major, a UGP leva a um fenótipo moderado associado à atividade residual da UGP, que ocorre devido a USP (LAMERZ et al., 2010). A estrutura das UGPs possui um 
arranjo estrutural comum que adotam uma estrutura tripartida com um pequeno domínio catalítico central, onde possui uma dobra em sanduíche $\alpha / \beta / \alpha$ semelhante à Rossmann e um domínio C-terminal em hélice $\beta$ (ARAGÃO et al., 2007; ROEBEN et al., 2006).

As UGPs de L. major e de plantas são semelhantes em sua ativação, ambas são ativas como monômeros (LAMERZ et al., 2006), que após a ligação do complexo Epiruno 2 a $L$. major UGP mostra alterações em sua conformidade envolvendo o domínio C-terminal em direção ao sítio ativo e rearranjos em alças funcionais do domínio catalítico (SETEINER et al., 2007) como observados na Figura 05. Os resultados residuais do docking molecular da proteína L. major UDP-sugar pyrophosphorylase (3ogz) com o Epiruno 2 obteve uma energia de ligação de $-6,71 \mathrm{Kcal}_{\text {.mol }}{ }^{-1}$ e uma constante de inibição de 12,16 $\mu \mathrm{M}$. O complexo resultou em uma ligação de hidrogênio no aminoácido Lys134, local em que acontece a maior interação molecular (Tabela 02). Os aminoácidos Asp271, Gln270, Glu126, Gly122, Gly123, His224, Leu124 e Val120 fazem as interações hidrofóbicas (Tabela 02). A imagem ilustrativa do docking molecular do complexo Epiruno $2 / 30 g z$ está disponível na Figura 05.

O docking molecular do tryparedoxin peroxidase de L. major (3tue) com o Epiruno 2 apresentou uma energia de ligação de $-6.58 \mathrm{Kcal} \mathrm{mol}^{-1}$ e uma constante de inibição de 14.91 $\mu \mathrm{M}$ (Tabela 02), mostrando atividade anti-tryparedoxin peroxidase de L. major. O 3tue tem sido um alvo atrativo para pesquisas in sílica por conter um metabolismo hidroperóxido dependente de tripanotiona, pois além desse parasita não conter catalase, também possui peroxidases dependentes de selênio, redutase da glutationa e da tioredoxina redutase e por possuir uma defesa antioxidante baseada em um sistema de enzimas dependente da tripanotiona ditiol único (N1, N8-bis (glutationilo) espermidina, T (SH) 2 ) (FLOHE, 2012). Mesmo sendo um alvo atrativo, pesquisas de novas alternativas de drogas são necessárias devido à baixa eficácia e segurança dos medicamentos combinado com a resistência aos medicamentos existentes (MALTEZOU, 2009). A imagem ilustrativa do docking molecular do complexo Epiruno $2 / 3$ tue está disponível na Figura 05.

A oligopeptidase B (OPB) é uma sirina peptidase com dibásico especificidade do substrato. Podendo ser encontrada em plantas, bactérias e patógenos tripanossomatídeos, tornando-se um fator de virulência e um alvo atrativo de pesquisas de compostos bioativos (BURLEIGH, 2002). A OPB de L. major (2xe4) contém dois domios, onde um é domio catalico e o outro é domio de hice. Eles são ligados entre si por uma regi de charneira (MCLUSKEY et al., 2010). São conhecidas apenas três drogas que inibem esta OPB de $L$. major, a pentamidina, diminazeno e suramina (MORTY et al., 1998; MCLUSKEY et al., 2010). A Epiruno 2 se apresenta como um agente biológico alternativo, onde demonstrou uma 
interação molecular com a OPB de L. major com uma energia de ligação de $-6.12 \mathrm{Kcal}^{\mathrm{mol}}{ }^{-1}$ e uma constante de inibição de $32.8 \mu \mathrm{M}$. O complexo formou três pontes de hidrogênio ligadas nos aminoácidos Ala80, Asp78 e Leu82 que é os locais que acontecem as maiores forças intermoleculares da ligação (Tabela 02). Os aminoácidos Ala77, Ala80, Asp78, Ile79, Leu82, Lys719, Thr724 fazem as interações hidrofóbicas (Tabela 02). A imagem ilustrativa da docking molecular entre a proteína 2xe4 e o Epiruno 2 está disponível na Figura 05.

Figura 05: Docking molecular. Epiruno $2 / 3$ ogz: a) ancoragem no sítio ativo do receptor, b) interação molecular entre o receptor e o ligante no sítio de ligação; Epiruno $2 / 3$ tue: c) ancoragem no sítio ativo do receptor, d) interação molecular entre o receptor e o ligante no sítio de ligação; Epiruno 2 /2xe4: e) interação molecular entre o receptor e o ligante no sítio de ligação.

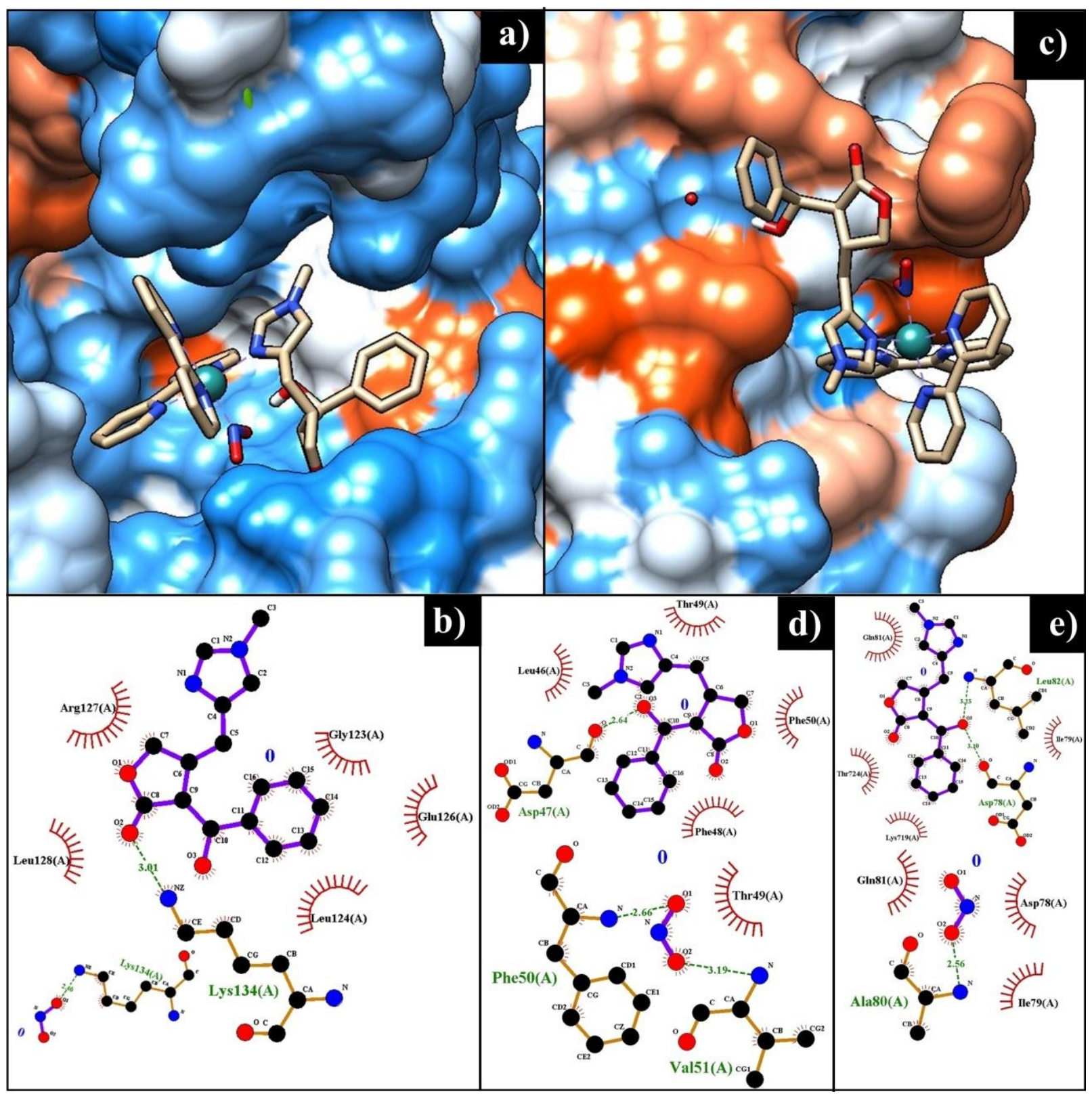


Os melhores resultados de interação molecular foram definidos pelo menor valor de energia de ligação através dos testes de docking molecular, onde os complexos Epiruno $2 / 5 \mathrm{nzg}$ e Epiruno $_{2} / 1 \mathrm{e} 7 \mathrm{w}$ obtiveram energias de ligação de $-10,51$ e $-10,68$ Kcal.mol ${ }^{-1}$ respectivamente, mostrando uma afinidade molecular gigantesca com os receptores de $L$. major, onde constam com uma constante de inibição de 19,74 nM e 14,8 nM. Além dessas duas proteínas, foi observado que o Epiruno 2 possui interação molecular com todos os alvos analisados de espécies de L. major. Também destacamos a $5 \mathrm{~g} 20$ que obteve um resultado considerável, com uma energia de ligação de $-9,65 \mathrm{Kcal} \mathrm{mol}^{-1}$ e uma constante de inibição de 83,81 nM. Esses alvos com maiores afinidades moleculares foram escolhidos para a realização dos ensaios in vitro.

\subsection{Ensaios in vitro da atividade antileishmania de um complexo metálico de rutênio com epiisopiloturina e óxido nítrico contra formas promastigotas de L. major.}

Nestes ensaios foram avaliados os efeitos leishmanicida do complexo metálico Epiruno $_{2}$ em parasitas de L. major na forma promastigota.

Tabela 03: Valores de IC-50 de promastigotas de L. major em presença de um complexo metálico Epiruno $_{2}$.

\section{EPIRUNO $_{2}$}

L. major

IC50
$800 \mu \mathrm{g} / \mathrm{mL}$

1103,896

O complexo Epiruno $_{2}$ inibiu $50,53 \%$ do crescimento das promastigotas a uma concentração de $800 \mu \mathrm{g} / \mathrm{mL}$ (Figura 06), uma redução significativa, analisando a concentração inibitória média $\left(\mathrm{CI}_{50}\right)$, onde o Epiruno 2 atinge essa taxa de inibição com a concentração de 1103,896 (Tabela 03).

Observa-se, que os resultados in silico são mais promissores que os resultados in vitro. Isso pode estar relacionado à área de superfície polar topológica (TPSA), que utiliza de grupos funcionais obtidos por um banco de dados de estruturas, evitando cálculos de estruturas 3D do ligante ou a confirmação de qual conformação biológica é relevante, esse método é usado em estruturas 2D para 14 conjuntos de diversos dados de atividades farmacológica. Essa metodologia é promissora dos descritores $2 \mathrm{D}$ clássicos, como LogP 
calculado (ClogP) e refratividade molar calculada (CMR) na literatura 2D-QSAR (PRASANNA; DOERKSEN, 2009).

A avaliação mostrou que o complexo Epiruno 2 possui atividade antileishmania, onde induziu uma redução significativa no crescimento do parasito da espécie de L. major, obtendo o percentual inibitório, com média de 30,26 a 50,53\% (Figura 06) de inibição, com concentrações de $400 \mu \mathrm{g} / \mathrm{mL}$ e $800 \mu \mathrm{g} / \mathrm{mL}$, respectivamente.

Figura 06: Média percentual de inibição do crescimento de promastigotas de L. major em presença do complexo metálico Epiruno $_{2}$.

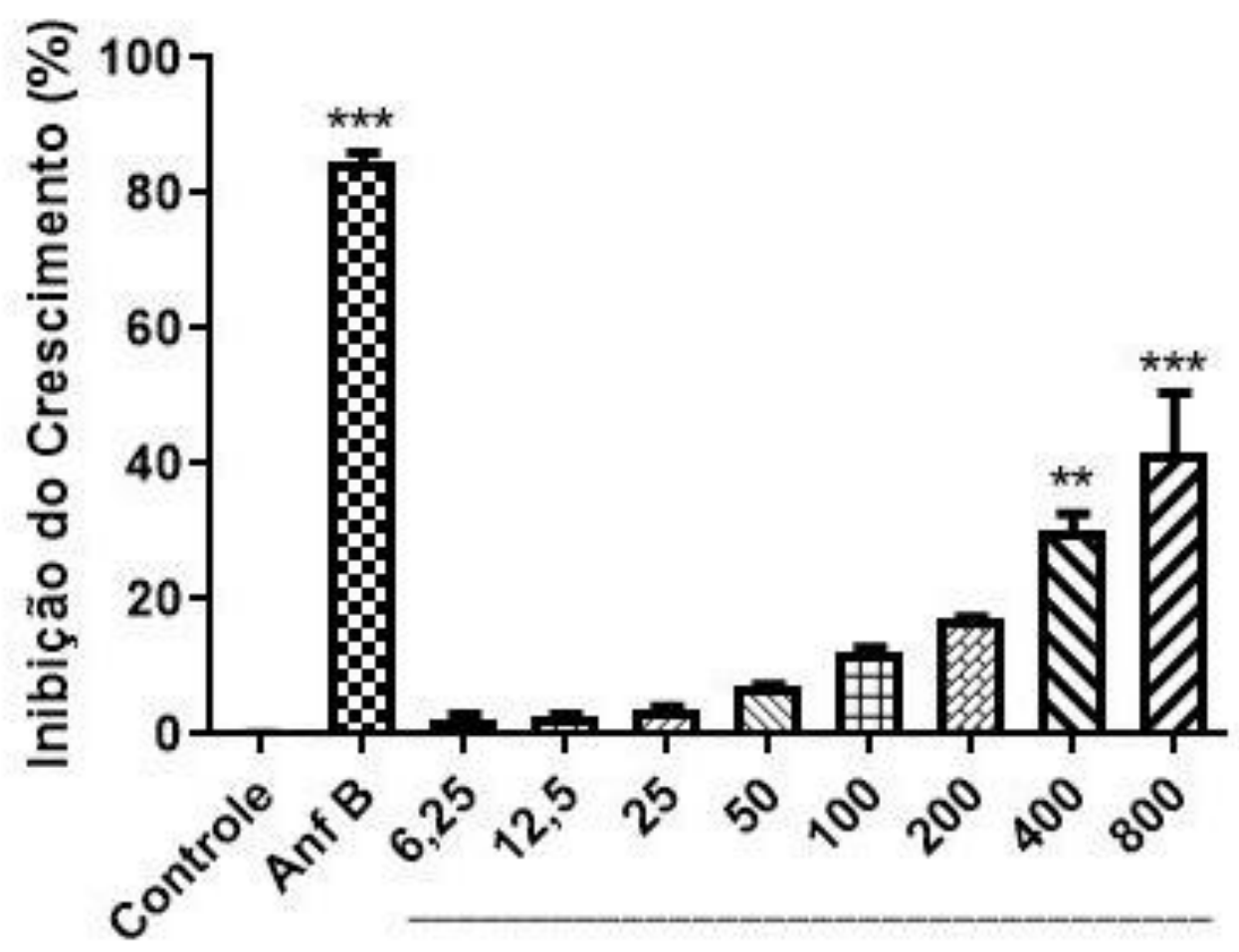

A descoberta de novos compostos químicos de ação biológica antileishmania já vem sendo realizada há muito tempo a partir de isolamento de extratos vegetais. Já existem diversos extratos que comprovaram sua ação antileishmanicida sobre forma promastigotas e amastigotas de Leshmania spp em ensaios in vitro. A terpenóides contém atividade antileishmania comprovada (SUAVAIN et al., 1996; CAMACHO et al., 2000), aminoglicosteróides e minosteróides (KAM et al., 1998), naftoquinonas (KAAYSER et al., 2000), chalconas (CHEN et al., 1993; BOECK et al., 2006), glicosídios iridóides (MITTAL et al., 1998), flavonóides (ARAÚJO et al., 1998), lignas (BARATA et al., 2000; Royo et al., 2003) e alcalóides (MAHIOU et al., 1994; FOURNET et al., 1996; QUEIROZ et al., 1996), todos esses compostos demonstram efeitos inibitórios contra leishmaniose. 
Apesar dos vários estudos microbiológicos, ainda são necessárias diversas análise de novos compostos extraídos de recursos naturais e sintéticos, pois a busca por novos potenciais ativos leishmanicida tem sido importante, já que as drogas existentes no mercado farmacológico possuem diversos efeitos colaterais, além da resistência do parasita aos antimoniais (SAMPAIO; SAMPAIO; MARSDEN et al., 1985; SCHNEIDER et al., 1992).

Esses resultados comprovam a atividade biológica antileishmania do complexo Epiruno $_{2}$, que apresentou atividade bioativa contra espécies de L. major tanto em estudos in sílico por docking molecular quanto por estudos microbiológicos através de ensaios in vitro. 


\section{CONSIDERAÇÕES FINAIS}

Evidenciou-se que o complexo metálico Epiruno $_{2}$ possui melhor parâmetro de afinidade para as proteínas $1 \mathrm{e} 7 \mathrm{w}$ e $5 \mathrm{nzg}$. Além desses dois alvos, foram constatado que o complexo possui boa taxa de energia de interação molecular no sítio ativo das demais proteínas de leishmania analisadas.

Os ensaios in vitro, comprovam a atividade biológica do complexo em promastigotas de espécies de L. major com inibições de crescimento significativas, podendo concluir através de estudos in sílico por docking molecular e ensaios in vitro que o Epiruno 2 possui atividade antileishmania.

Estudos futuros serão realizados para avaliar o potencial terapêutico do Epiruno 2 no tratamento da leishmaniose cutânea em modelo experimental. 


\section{REFERÊNCIAS}

ALVAR, Jorge et al. Leishmaniasis worldwide and global estimates of its incidence. PloS one, v. 7, n. 5, p. e35671, 2012.

ANDREI, C. C et al. Da Química Medicinal à Química Combinatória e Modelagem Molecular: Um Curso Prático, São Paulo: Manole, 2012.

ARAGÃO, David et al. The complex of Sphingomonas elodea ATCC 31461 glucose-1phosphate uridylyltransferase with glucose-1-phosphate reveals a novel quaternary structure, unique among nucleoside diphosphate-sugar pyrophosphorylase members. Journal of bacteriology, v. 189, n. 12, p. 4520-4528, 2007.

ARAKAKI TL et al. Characterization of Trypanosoma brucei dihydroorotate dehydrogenase as a possible drug target; structural, kinetic and RNAi studies. Mol Microbiol 2008; 68: 37 50 .

ARAUJO, C. A. C et al. Antileishmanial activity of compounds extracted and characterized from Centrolobium sclerophyllum. Phytochemistry, v. 49, n. 3, p. 751-754, 1998.

Ashford RW 2000. The leishmaniasis as emerging and reemerging zoonoses. Int J Parasitol 30: $1269-1281$.

BARATA, Lauro ES et al. Anti-leishmanial activity of neolignans from Virola species and synthetic analogues. Phytochemistry, v. 55, n. 6, p. 589-595, 2000.

BERMAN, H. M.; WESTBROOK, J.; FENG, Z.; GILLILAND, G.; BHAT, T. N.; WEISSIG, H.; SHINDYALOV, I. N.; BOURNE, P. E. The Protein Data Bank. Nucleic Acids Res. v.28, p.235-242, 2000.

BERMAN, J.D. Treatment of New World cutaneous and mucosal leishmaniasis. Clin. Dermatol., v. 14, p. 519-522, 1996.

BOECK, Paula et al. Synthesis of chalcone analogues with increased antileishmanial activity. Bioorganic \& medicinal chemistry, v. 14, n. 5, p. 1538-1545, 2006.

BRASIL. Secretaria de Vigilância em Saúde. Departamento de Vigilância Epidemiológica. Manual de vigilância e controle da leishmaniose visceral. 1. ed. Brasília: Ministério da Saúde, 2014. 120 p.

BRELIVET, Yann et al. Signature of the oligomeric behaviour of nuclear receptors at the sequence and structural level. EMBO reports, v. 5, n. 4, p. 423-429, 2004.

BRITTO, Constança et al. Conserved linkage groups associated with large-scale chromosomal rearrangements between Old World and New World Leishmania genomes. Gene, v. 222, n. 1, p. 107-117, 1998. 
BRYK, Ruslana; GRIFFIN, Patrick; NATHAN, Carl. Peroxynitrite reductase activity of bacterial peroxiredoxins. Nature, v. 407, n. 6801, p. 211, 2000.

BURLEIGH, Barbara A.; WOOLSEY, Aaron M. Cell signalling and Trypanosoma cruzi invasion. Cellular microbiology, v. 4, n. 11, p. 701-711, 2002.

BUTANI, D., Yewale, C., Misra, A., 2014. Amphotericin B topical microemulsion: formulation, characterization and evaluation. Colloids Surf, B. 116, 351-358.

CALDEIRA, L. R. et al. Nanoemulsions loaded with amphotericin B: a new approach for the treatment of leishmanisis. Eur J Pharm Sci. 70, 125-131, 2015.

CARVALHO, R. F et al. Leishmanicidal activity of amphotericin B encapsulated in PLGADMSA nanoparticles to treat cutaneous leishmaniasis in C57BL/6 mice. Exp Parasitol. 135, 217-222, 2013.

CARNEIRO, S. M. P et al. The cytotoxic and antileishmanial activity of extracts and fractions of leaves and fruits of Aaadirachta indica (A juss.). Biol. Res. v.45, n.2, p.111-116, 2012.

CAVAZZUTI, Antonio et al. Discovery of potent pteridine reductase inhibitors to guide antiparasite drug development. Proceedings of the National. Academy of Sciences, v. 105, n. 5, p. 1448-1453, 2008.

CHELESKI J et al. Novel insights for dihydroorotate dehydrogenase class 1A inhibitors discovery. Eur J Med Chem 2010; 45: 5899-909.

CHEN, Ming et al. Licochalcone A, a novel antiparasitic agent with potent activity against human pathogenic protozoan species of Leishmania. Antimicrobial agents and chemotherapy, v. 37, n. 12, p. 2550-2556, 1993.

CHOW, M. et al. Myristylation of picornavirus capsid protein VP4 and its structural significance. Nature, v. 327, n. 6122, p. 482, 1987.

CROFT, Simon L.; COOMBS, Graham H. Leishmaniasis-current chemotherapy and recent advances in the search for novel drugs. Trends in parasitology, v. 19, n. 11, p. 502-508, 2003.

CROFT, S. L.; SEIFERT, K. Miltefosine: interactions with other anti-leishmanial drugs. In: 3rd World Congress on Leishmaniosis. 2005. p. 10-15.

CROFT, S. L. Chemotherapy of human leishmaniasis and trypanosomiasis. Trypanosomiasis and leishmaniasis; biology and control, p. 245-257, 1997.

DEFREES, Shawn A. et al. Structure-activity relationships of pyrimidines as dihydroorotate dehydrogenase inhibitors. Biochemical pharmacology, v. 37, n. 20, p. 3807-3816, 1988.

DEL RAYO CAMACHO, Maria et al. Terpenoids from Guarea rhophalocarpa. Phytochemistry, v. 56, n. 2, p. 203-210, 2001. 
DESCOTEAUX, Albert; TURCO, Salvatore J. Glycoconjugates in Leishmania infectivity. Biochimica et Biophysica Acta (BBA)-Molecular Basis of Disease, v. 1455, n. 2-3, p. 341-352, 1999.

DUTRA, Luiz Antônio et al. Leishmanicidal Activity of Novel Synthetic Furoxan and Benzofuroxan Derivatives. Antimicrobial agents and chemotherapy, p. AAC. 00052-14, 2014.

FIGUEIREDO, K. A. et al. Prospecting Biochemical Targets for in silico Study for Antileishmania Chemotherapy. REVISTA VIRTUAL DE QUIMICA, v. 10, n. 5, p. 1485$1501,2018$.

FLOHÉ, Leopold. The trypanothione system and the opportunities it offers to create drugs for the neglected kinetoplast diseases. Biotechnology advances, v. 30, n. 1, p. 294-301, 2012.

FOURNET, Alain et al. In vivo efficacy of oral and intralesional administration of 2substituted quinolines in experimental treatment of new world cutaneous leishmaniasis caused by Leishmania amazonensis. Antimicrobial Agents and Chemotherapy, v. 40, n. 11, p. 2447-2451, 1996.

FÜHRING, Jana et al. Octamerization is essential for enzymatic function of human UDPglucose pyrophosphorylase. Glycobiology, v. 23, n. 4, p. 426-437, 2013.

GARBIN SOBRINHO, Larissa Lorenn et al. Complexos de rutênio (II) contendo 2mercaptoimidazol e derivados: síntese, caracterização e avaliação da atividade biológica. 2015.

GASTEIGER, Johann; MARSILI, Mario. Iterative partial equalization of orbital electronegativity-a rapid access to atomic charges. Tetrahedron, v. 36, n. 22, p. 3219-3228, 1980.

Goodsell DS. Acoplamento computacional de complexos biomoleculares com o AutoDock. Em: Golemis EA, Adams PD, editores. Interações proteína-proteína: um manual de clonagem molecular. 2a ed. Nova Iorque: Cold Spring Harbor Laboratory Press; 2005.

GOODSELL, David S.; MORRIS, Garrett M.; OLSON, Arthur J. Automated docking of flexible ligands: applications of AutoDock. Journal of Molecular Recognition, v. 9, n. 1, p. $1-5,1996$.

GUIDO, Rafael VC; ANDRICOPULO, Adriano D .; OLIVA, Glaucius. Drug planning, biotechnology and medical chemistry: applications in infectious diseases. advanced studies, v. 24, n. 70, p. 81-98, 2010.

GUIMARAES, Maria A. et al. Nanopharmaceutical approach of epiisopiloturine alkaloid carried in liposome system: preparation and in vitro schistosomicidal activity. Journal of nanoscience and nanotechnology, v. 14, n. 6, p. 4519-4528, 2014.

HANDMAN, Emanuela. Leishmaniasis: current status of vaccine development. Clinical microbiology reviews, v. 14, n. 2, p. 229-243, 2001. 
HEHRE, W. J. RADON, L. Schelyer, P. vR, and Pople, JA Molecular Orbital Theory. J. 1986.

HEPBURN, N. C. et al. Hepatotoxicity of sodium stibogluconate therapy for American cutaneous leishmaniasis. Transactions of the Royal Society of Tropical Medicine and Hygiene, v. 88, n. 4, p. 453-455, 1994.

ILG, T. Proteophosphoglycans of Leishmania Parasitol. Today 2000, 16, 489- 497 DOI: 10.1016/S0169-4758(00)01791-9.

IVES AC, Peacock CS, WortheyEa, Murphy L, Aggarwal G, Berriman M, ET al. The genomeofthekinetoplastid parasite, Leishmania major. Science. 2005;309(5733):436-42.

JAFFE, Charles L.; DWYER, Dennis M. Extracellular release of the surface metalloprotease, gp63, from Leishmania and insect trypanosomatids. Parasitology research, v. 91, n. 3, p. 229-237, 2003.

JOHNSON, D. Russell et al. Genetic and biochemical studies of protein Nmyristoylation. Annual review of biochemistry, v. 63, n. 1, p. 869-914, 1994.

KAM, Toh-Seok et al. Cytotoxic and leishmanicidal aminoglycosteroids and aminosteroids from Holarrhena curtisii. Journal of natural products, v. 61, n. 11, p. 1332-1336, 1998.

KAYSER, Oliver et al. In vitro leishmanicidal activity of monomeric and dimeric naphthoquinones. Acta Tropica, v. 76, n. 2, p. 131-138, 2000.

KHALAF, Abedawn I. et al. Structure-based design and synthesis of antiparasitic pyrrolopyrimidines targeting pteridine reductase 1 . Journal of medicinal chemistry, v. 57, n. 15, p. 6479-6494, 2014.

Lamerz, A. C.; Haselhorst, T.; Bergfeld, A. K.; von Itzstein, M.; Gerardy-Schahn, R. Molecular cloning of the Leishmania major UDPglucose pyrophosphorylase, functional characterization, and ligand binding analyses using NMR spectroscopy. J. Biol. Chem. 2006, $281,16314-16322$.

LAMERZ, Anne-Christin et al. Deletion of UDP-glucose pyrophosphorylase reveals a UDPglucose independent UDP-galactose salvage pathway in Leishmania major. Glycobiology, v. 20, n. 7, p. 872-882, 2010.

LAMERZ, Anne-Christin et al. Molecular cloning of the Leishmania major UDP-glucose pyrophosphorylase, functional characterization, and ligand binding analyses using NMR spectroscopy. Journal of Biological Chemistry, v. 281, n. 24, p. 16314-16322, 2006.

LASCU, Ioan; GONIN, Philippe. The catalytic mechanism of nucleoside diphosphate kinases. Journal of bioenergetics and biomembranes, v. 32, n. 3, p. 237-246, 2000.

LAUDET, Vincent; GRONEMEYER, Hinrich. The nuclear receptor factsbook. Gulf Professional Publishing, 2002. 
LIMA, Sofia A. Costa et al. Crucial CD8+ T-lymphocyte cytotoxic role in amphotericin B nanospheres efficacy against experimental visceral leishmaniasis. Nanomedicine: Nanotechnology, Biology and Medicine, v. 10, n. 5, p. e1021-e1030, 2014.

MAHIOU, V. et al. New aporphine alkaloids from Guatteria foliosa. Journal of natural products, v. 57, n. 7, p. 890-895, 1994.

MALTEZOU, Helena C. Drug resistance in visceral leishmaniasis. BioMed Research International, v. 2010, 2009.

MCLUSKEY, Karen et al. A estrutura cristalina da oligopeptidase B de Leishmania major fornece informações sobre as propriedades enzimáticas de um fator de virulência do tripanossomatídeo. Journal of Biological Chemistry, p. jbc. M110 156679, 2010.

MISHRA, Arjun K. et al. Descoberta de novos inibidores da nucleosídeo difosfatase quinase de Leishmania (NDK) com base em sua caracterização estrutural e funcional. Journal of Computer-Aided Molecular Design, v. 31, n. 6, p. 547-562, 2017.

MITTAL, Navdha et al. Protective effect of Picroliv from Picrorhiza kurroa against Leishmania donovani infections in Mesocricetus auratus. Life sciences, v. 63, n. 20, p. 18231834, 1998.

MORRIS, Garrett M.; HUEY, Ruth; OLSON, Arthur J. Using autodock for ligand-receptor docking. Current protocols in bioinformatics, v. 24, n. 1, p. 8.14. 1-8.14. 40, 2008.

MORRIS, Garrett M. et al. Automated docking using a Lamarckian genetic algorithm and an empirical binding free energy function. Journal of computational chemistry, v. 19, n. 14, p. 1639-1662, 1998.

MORTY, Rory E. et al. A trypanosome oligopeptidase as a target for the trypanocidal agents pentamidine, diminazene and suramin. FEBS letters, v. 433, n. 3, p. 251-256, 1998.

MPAMHANGA, Chidochangu P. et al. One scaffold, three binding modes: novel and selective pteridine reductase 1 inhibitors derived from fragment hits discovered by virtual screening. Journal of medicinal chemistry, v. 52, n. 14, p. 4454-4465, 2009.

MURRAY, Henry W. et al. Advances in leishmaniasis. The Lancet, v. 366, n. 9496, p. 1561$1577,2005$.

NARE, Bakela; HARDY, Larry W.; BEVERLEY, Stephen M. The roles of pteridine reductase 1 and dihydrofolate reductase-thymidylate synthase in pteridine metabolism in the protozoan parasite Leishmania major. Journal of Biological Chemistry, v. 272, n. 21, p. 13883-13891, 1997.

PALFEY, Bruce A.; BJÖRNBERG, Olof; JENSEN, Kaj Frank. Specific inhibition of a family $1 \mathrm{~A}$ dihydroorotate dehydrogenase by benzoate pyrimidine analogues. Journal of medicinal chemistry, v. 44, n. 18, p. 2861-2864, 2001. 
PARKIN, David W. et al. Nucleoside hydrolase from Crithidia fasciculata. Metabolic role, purification, specificity, and kinetic mechanism. Journal of Biological Chemistry, v. 266, n. 31, p. 20658-20665, 1991.

PARKIN, David W. et al. Isozyme-specific transition state inhibitors for the trypanosomal nucleoside hydrolases. Biochemistry, v. 36, n. 12, p. 3528-3534, 1997.

PARKS, R. E. et al. Purine metabolism in primitive erythrocytes. Comparative Biochemistry and Physiology--Part B: Biochemistry and, v. 45, n. 2, p. 355-364, 1973.

PETTERSEN, E.F.; GODDARD, T.D.; HUANG, C.C.; COUCH, G.S.; GREENBLATT, D.M.; MENG, E.C.; FERRIN, T.E. UCSF Chimera-a visualization system for exploratory research and analysis. J. Comput. Chem. v.25, p.1605-1612, 2004.

POPLE, John A.; BINKLEY, J. Stephen; SEEGER, Rolf. Theoretical models incorporating electron correlation. International Journal of Quantum Chemistry, v. 10, n. S10, p. 1-19, 1976.

PRASANNA, S.; DOERKSEN, R. J. Topological polar surface area: a useful descriptor in 2D-QSAR. Current medicinal chemistry, v. 16, n. 1, p. 21-41, 2009.

PINTO PINHEIRO, Matheus; DA SILVA EMERY, Flavio; CRISTINA NONATO, M. Target sites for the design of anti-trypanosomatid drugs based on the structure of dihydroorotate dehydrogenase. Current pharmaceutical design, v. 19, n. 14, p. 2615-2627, 2013.

QUEIROZ, Emerson F. et al. Pessoine and spinosine, two catecholic berbines from Annona spinescens. Journal of Natural Products, v. 59, n. 4, p. 438-440, 1996.

RAMOS, Ricardo Martins et al. Interaction of wild type, G68R and L125M isoforms of the arylamine-N-acetyltransferase from Mycobacterium tuberculosis with isoniazid: a computational study on a new possible mechanism of resistance. Journal of molecular modeling, v. 18, n. 9, p. 4013-4024, 2012.

Rangel EF, Lainson R 2009. Proven and putative vectors of American cutaneous leishmaniasis in Brazil: aspects of their biology and vectorial competence. Mem Inst Oswaldo Cruz 104(7).

RAPPOPORT, Dmitrij; FURCHE, Filipp. Property-optimized Gaussian basis sets for molecular response calculations. The Journal of chemical physics, v. 133, n. 13, p. 134105, 2010.

RATH, Susanne et al. Antimonials employed in the treatment of leishmaniaisis: the state of the art. Química Nova, v. 26, n. 4, p. 550-555, 2003.

ROCHA, Jefferson A. et al. Computational quantum chemistry, molecular docking, and ADMET predictions of imidazole alkaloids of Pilocarpus microphyllus with schistosomicidal properties. PloS one, v. 13, n. 6, p. e0198476, 2018. 
ROEBEN, Annette et al. Structural basis for subunit assembly in UDP-glucose pyrophosphorylase from Saccharomyces cerevisiae. Journal of molecular biology, v. 364, n. 4, p. 551-560, 2006.

ROYO, V. A. et al. Biological activity evaluation of dibenzilbutirolactones lignans derivatives against Leishmania braziliensis. Revista Brasileira de Farmacognosia, v. 13, p. 18-21, 2003.

RUIZ, Helga K. et al. New amphotericin B-gamma cyclodextrin formulation for topical use with synergistic activity against diverse fungal species and Leishmania spp. International journal of pharmaceutics, v. 473, n. 1-2, p. 148-157, 2014.

SACKS, David L. Leishmania-sand fly interactions controlling species-specific vector competence: Microreview. Cellular microbiology, v. 3, n. 4, p. 189-196, 2001.

SALERNO, Claudia et al. Lipid-based microtubes for topical delivery of Amphotericin B. Colloids and Surfaces B: Biointerfaces, v. 107, p. 160-166, 2013.

SAMPAIO S. A. P.; RIVITTI, E.A. Dermatologia. 3. Ed. São Paulo: Artes Médicas; p. 75564. 2008.

SAMPAIO, R. N. R.; SAMPAIO, J. H. D.; MARSDEN, P. D. Pentavalent antimonial treatment in mucosal leishmaniasis. The Lancet, v. 325, n. 8437, p. 1097, 1985.

SANNER, Michel F. et al. Python: a programming language for software integration and development. J Mol Graph Model, v. 17, n. 1, p. 57-61, 1999.

SAUVAIN, Michel et al. Isolation of leishmanicidal triterpenes and lignans from the Amazonian liana Doliocarpus dentatus (Dilleniaceae). Phytotherapy research, v. 10, n. 1, p. $1-4,1996$.

SCHNEIDER, Pascal et al. Leishmania major: differential regulation of the surface metalloprotease in amastigote and promastigote stages. Experimental parasitology, v. 75, n. 2, p. 196-206, 1992.

SCHNURR, Judy A. et al. UDP-sugar pyrophosphorylase is essential for pollen development in Arabidopsis. Planta, v. 224, n. 3, p. 520-532, 2006.

SCOTT, Phillip; NOVAIS, Fernanda O. Cutaneous leishmaniasis: immune responses in protection and pathogenesis. Nature Reviews Immunology, v. 16, n. 9, p. 581, 2016.

SOLIS, Francisco J.; WETS, Roger J.-B. Minimization by random search techniques. Mathematics of operations research, v. 6, n. 1, p. 19-30, 1981.

SOUZA, Tatiana ACB et al. Molecular adaptability of nucleoside diphosphate kinase $b$ from trypanosomatid parasites: stability, oligomerization and structural determinants of nucleotide binding. Molecular BioSystems, v. 7, n. 7, p. 2189-2195, 2011. 
STEINER, Thomas et al. Open and closed structures of the UDP-glucose pyrophosphorylase from Leishmania major. Journal of Biological Chemistry, v. 282, n. 17, p. 13003-13010, 2007.

STUART, Ken et al. Kinetoplastids: related protozoan pathogens, different diseases. The Journal of clinical investigation, v. 118, n. 4, p. 1301-1310, 2008.

TANAKA, Nobutada et al. Crystal structure of the ternary complex of mouse lung carbonyl reductase at $1.8 \AA$ resolution: the structural origin of coenzyme specificity in the short-chain dehydrogenase/reductase family. Structure, v. 4, n. 1, p. 33-45, 1996.

TULLOCH, Lindsay B. et al. Structure-based design of pteridine reductase inhibitors targeting African sleeping sickness and the leishmaniases. Journal of medicinal chemistry, v. 53, n. 1, p. 221-229, 2009.

VOIGTLÄNDER, Hans-Walter et al. Epiisopiloturin, ein neues Pilocarpus-Alkaloid. Archiv der Pharmazie, v. 311, n. 11, p. 927-935, 1978.

K VYAS, V.; GHATE, M. Recent developments in the medicinal chemistry and therapeutic potential of dihydroorotate dehydrogenase (DHODH) inhibitors. Mini reviews in medicinal chemistry, v. 11, n. 12, p. 1039-1055, 2011.

WINCKER, Patrick et al. The Leishmania genome comprises 36 chromosomes conserved across widely divergent human pathogenic species. Nucleic acids research, v. 24, n. 9, p. 1688-1694, 1996.

WRIGHT, Megan H. et al. Protein myristoylation in health and disease. Journal of chemical biology, v. 3, n. 1, p. 19-35, 2010. 